\title{
Detecting Sea-Level Hazards: Simple Regression-Based Methods for Calculating the Acceleration of Sea Level
}

By Kara S. Doran, Peter A. Howd, and Asbury H. Sallenger, Jr.

Open-File Report 2015-1187

U.S. Department of the Interior

U.S. Geological Survey 


\section{U.S. Department of the Interior \\ SALLY JEWELL, Secretary}

\section{U.S. Geological Survey \\ Suzette M. Kimball, Acting Director}

U.S. Geological Survey, Reston, Virginia: 2015

For more information on the USGS-the Federal source for science about the Earth, its natural and living resources, natural hazards, and the environment-visit http://www.usgs.gov or call 1-888-ASK-USGS.

For an overview of USGS information products, including maps, imagery, and publications, visit http://www.usgs.gov/pubprod.

Any use of trade, firm, or product names is for descriptive purposes only and does not imply endorsement by the U.S. Government.

Although this information product, for the most part, is in the public domain, it also may contain copyrighted materials as noted in the text. Permission to reproduce copyrighted items must be secured from the copyright owner.

Suggested citation:

Doran, K.S., Howd, P.A., and Sallenger, A.H., Jr., 2015, Detecting sea-level hazards-Simple regression-based methods for calculating the acceleration of sea level: U.S. Geological Survey Open-File Report 2015-1187, 28 p., http://dx.doi.org/10.3133/ofr20151187.

ISSN 2331-1258 (online) 


\section{Contents}

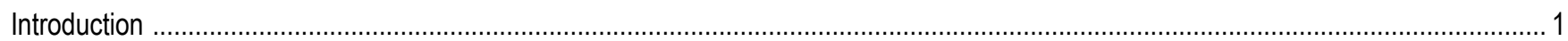

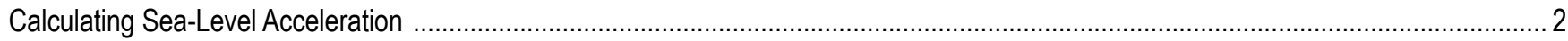

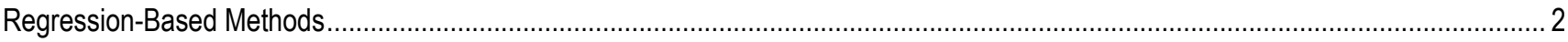

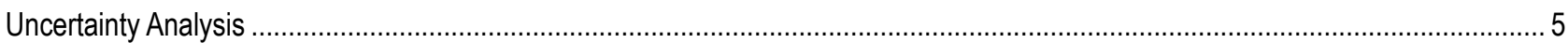

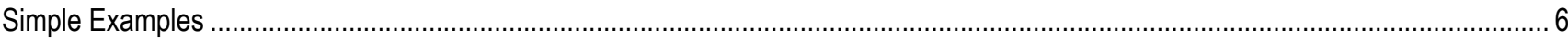

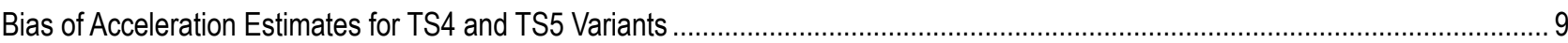

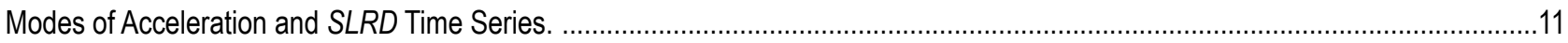

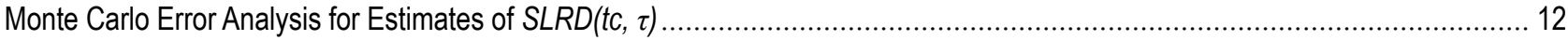

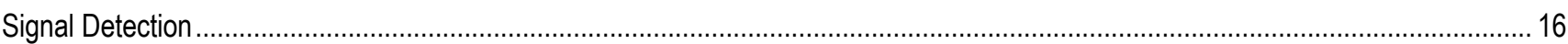

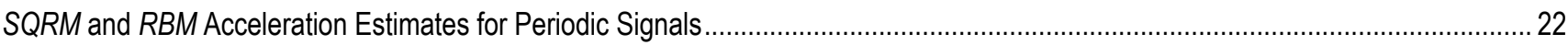

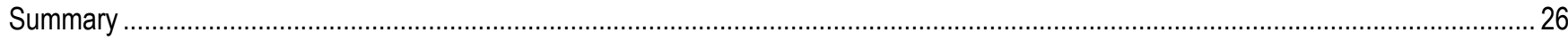

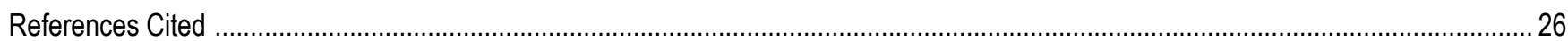

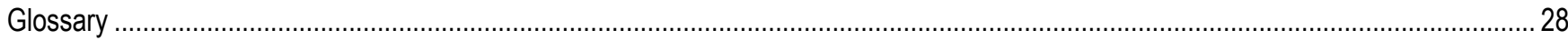

\section{Figures}

1. Acceleration estimates for TS1, TS2, and TS3

2. Examples of TS4 and TS5 variants; TS4, where the start year of a constant acceleration within the time series is initiated, and TS5, where the start year of an increased rate of $S L$ rise is initiated

8

3. Acceleration estimates for TS4 ${ }_{1950}$ (top) and $\mathrm{TS}_{1950}$ (bottom) using the three regression-based estimators .................................. 9

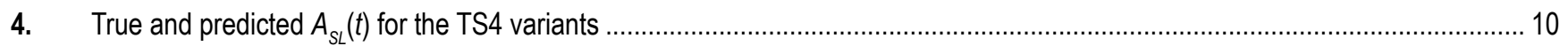

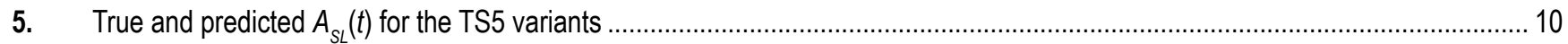

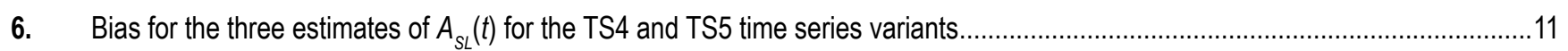

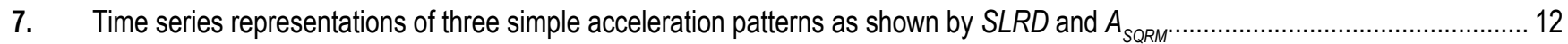

8. Examples of time series with added $A R(1)$ noise at a variance level $\left(2,500 \mathrm{~mm}^{2}\right)$ representative of U.S. east coast tide gages .... 13

9. Summary of Monte Carlo simulation for $\operatorname{SLRD}(1950,60)$, using different noise formulations with equal variance in conjunction

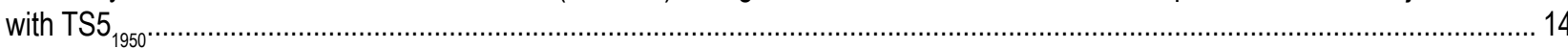

10. Summary probability distributions for the $10^{4}$ Monte Carlo predictions of $\operatorname{SLRD}(1950,60)$ for three noise types and three

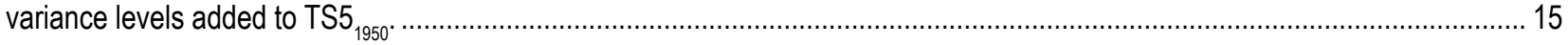

11. Effect of window duration $\tau$ on the distribution of estimated SLRD for fixed noise type and variance...................................... 16

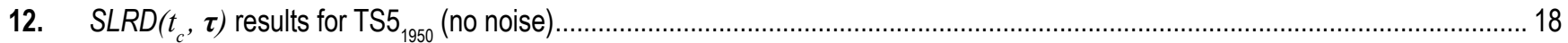

13. SLRD estimates for time series TS5 ${ }_{1950}$ with Guassian (white) noise at $100 \%$ observed level ................................................ 19

14. Dimensionless representation of ensemble-averaged $S L R D$ time series with multiple $A R(1)$ noise levels and different window

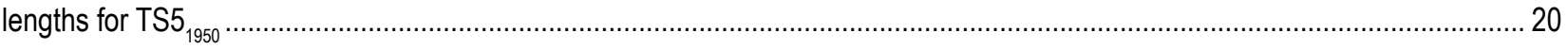

15. Hypothetical time series showing the gradual separation of point clouds after a rate increase from $2 \mathrm{~mm} / \mathrm{yr}$ to $4 / \mathrm{mm}$ yr at

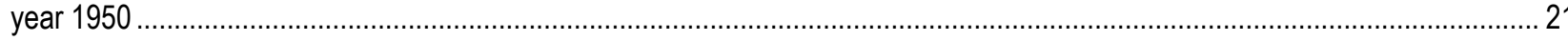

16. A simple example of $S L R D$ representation of a periodic fluctuation in sea level ..................................................................2 23

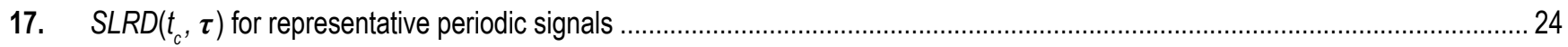




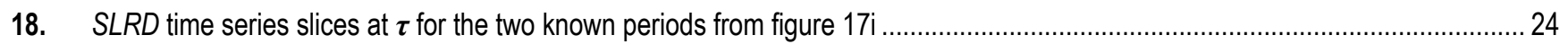

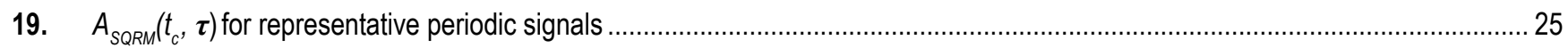

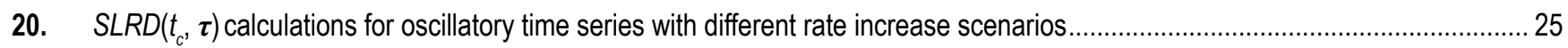

\section{Tables}

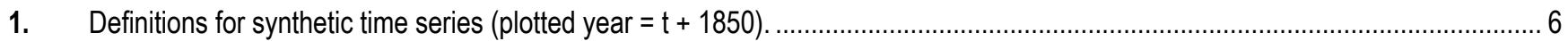

2. Mean acceleration/SLRD estimates with $2 \sigma$ errors on the basis of 10,000 trials. "Adjusted" indicates that the standard error has been corrected for serial correlation as described in the section "Uncertainty Analysis". 


\section{Conversion Factors}

\section{SI to Inch/Pound}

\begin{tabular}{lll}
\hline \multicolumn{1}{c}{ Multiply } & By & To obtain \\
\hline centimeter (cm) & 0.3937 & inch (in.) \\
millimeter (mm) & 0.03937 & inch (in.) \\
meter (m) & 3.281 & foot (ft) \\
kilometer (km) & 0.6214 & mile (mi) \\
kilometer (km) & 0.5400 & mile, nautical (nmi) \\
meter (m) & 1.094 & yard (yd) \\
\hline
\end{tabular}

Temperature in degrees Celsius $\left({ }^{\circ} \mathrm{C}\right)$ may be converted to degrees Fahrenheit $\left({ }^{\circ} \mathrm{F}\right)$ as follows:

${ }^{\circ} \mathrm{F}=\left(1.8 \mathrm{x}^{\circ} \mathrm{C}\right)+32$ 


\title{
Detecting Sea-Level Hazards: Simple Regression-Based Methods for Calculating the Acceleration of Sea Level
}

\author{
By Kara S. Doran, Peter A. Howd, and Asbury H. Sallenger, Jr.
}

\section{Introduction}

This report documents the development of statistical tools used to quantify the hazard presented by the response of sea-level elevation to natural or anthropogenic changes in climate and ocean circulation. A hazard is a physical process (or processes) that, when combined with vulnerability (or susceptibility to the hazard), results in risk. This study presents the development and comparison of new and existing sea-level analysis methods, exploration of the strengths and weaknesses of the methods using synthetic time series, and when appropriate, synthesis of the application of the method to observed sea-level time series. These reports are intended to enhance material presented in peer-reviewed journal articles where it is not always possible to provide the level of detail that might be necessary to fully support or recreate published results.

The purpose of this report is to document and compare three simple methodologies that have previously been used to provide estimates with associated errors of the acceleration of sea-level elevation. These techniques have been used by coastal scientists and planners in assessing coastal risk over a wide range of spatial and temporal scales (for example, Dasgupta and others, 2007; Edwards, 2008; Frazier and others, 2010). Because relative sea-level (SL) elevation time series contain energetic fluctuations at many time scales, extracting what can be relatively small rate and acceleration signals (along with estimates of the error) from much larger "noise" has proven to be both difficult and controversial. Acceleration is a preferred measure of $S L$ response to recent changes in the Earth's climate because over time scales of 100 years or less slow vertical land motions (such as glacial isostatic adjustment) contribute only to the linear signal and not to acceleration, thus reducing the complexity of the analysis. Hence acceleration is useful if the goal of a study is to characterize and quantify the hazard associated with the changing relative elevation of water with respect to land on decadal time scales. Although in some cases it may be necessary to determine the cause of relative sea level rise, as a first step, it is important to accurately estimate the magnitude of the threat.

Most researchers agree that global sea level $(G S L)$ rose persistently through much of the $20^{\text {th }}$ century at about 1.5-2.0 millimeters per year (mm/yr) (for example, Douglas, 1991; Holgate and Woodworth, 2004; Merrifield and others, 2009; Church and White, 2011). There is far less agreement about whether the rate of sea-level rise $(S L R)$ is increasing (that is, an acceleration in $S L$ ). More recently, Houston and Dean (2011a) reported negative acceleration of $S L$ in the United States and around the world during much of the 20th century. Rahmstorf and Vermeer (2011) argued that Houston and Dean's (2011a) results were biased by their choice of 1930 as a start date for their input data and that this choice assured they would detect no positive acceleration. Rahmstorf and Vermeer (2011) further contradicted Houston and Dean (2011a) by showing positive acceleration in the global sea-level dataset of Church and White (2006) in which a more recent range of start dates was used. Watson (2011) found evidence in Australia and New Zealand of negative $S L$ acceleration similar in some respects to what Houston and Dean (2011a) reported for the United States. Unlike Houston and Dean (2011a), however, Watson (2011) qualitatively reported recent acceleration in Australia that was not captured by his analysis meth- 
odology. More recently, Sallenger and others (2012) defined a regional hotspot of sea-level acceleration on the east coast of North America from Cape Hatteras, North Carolina, into the maritime provinces of Canada.

These recent studies, and most of their predecessors, use tide gage data to quantify $S L$ acceleration, $A_{S L}(t)$. In the current study, three techniques were used to calculate acceleration from tide gage data, and of those examined, it was determined that the two techniques based on sliding a regression window through the time series are more robust compared to the technique that fits a single quadratic form to the entire time series, particularly if there is temporal variation in the magnitude of the acceleration. The single-fit quadratic regression method has been the most commonly used technique in determining acceleration in tide gage data. The inability of the single-fit method to account for time-varying acceleration may explain some of the inconsistent findings between investigators. Properly quantifying $A_{S L}(t)$ from field measurements is of particular importance in evaluating numerical models of past, present, and future $S L R$ resulting from anticipated climate change.

\section{Calculating Sea-Level Acceleration}

Acceleration of sea-level elevation is strictly defined as the second derivative of the elevation time series with respect to time. Although acceleration could be directly estimated by twice calculating the first differences between points, the resulting $A_{S L}(t)$ is generally too noisy to be of practical use. Some degree of smoothing is required, either applied initially to the elevation time series or to the acceleration estimates. Three methods are reviewed for calculating smoothed estimates of acceleration where the smoothing is imbedded in the application of ordinary least squares regression analysis. There are two primary benefits of using regressions to estimate accelerations. First, statistical errors are easily assigned to the estimated accelerations. Second, the methods themselves are based on elementary statistics, providing a reasonable entry point to the problem before more advanced time series analysis techniques are introduced.

\section{Regression-Based Methods}

A large number of authors, most recently Houston and Dean (2011a), Woodworth and others (2011), and Watson (2011), have used a single-fit quadratic regression method $(Q R M)$ as a tool to calculate the time-averaged acceleration of a sea-level elevation time series as

$$
A_{Q R M}=2 c
$$

where $A_{Q R M}$ is the estimated acceleration of the series using the quadratic regression method, and $2 c$ is the second derivative with respect to time $(t)$ of a quadratic equation fit to the sea-level data, using the ordinary least squares error criterion:

$$
S L(t)=a+b t+c t^{2}+\varepsilon(t)
$$

where $S L(t)$ is the measured sea-level elevation time series, and $\varepsilon(t)$ is the residual error. The underlying assumption in the choice of this calculation method is that the regression coefficients are constant over the duration of the record so that $A_{S L}(t)=A_{Q R M}$. 
$A_{Q R M}$ is an estimate of the average acceleration occurring over the duration of the time series used in the regression. If the duration of a given sea-level record is varied and significant changes in $A_{Q R M}$ occur, acceleration during any given time period within the record may vary considerably from the estimate over the entire time period, and the average acceleration will vary depending on what portions of the record are included. In the worst case, a time-varying acceleration may result in the time series being poorly approximated with a quadratic expression. These problems cast doubt on the appropriateness of the $Q R M$ results for comparisons either through time within a given record or between records with different start or end dates (see Jevrejeva and others, 2008; Rahmstorf and Vermeer, 2011; Sallenger and others, 2012).

Jevrejeva and others (2008) recognized the issues associated with assuming constant acceleration over an entire record and reported results from a sliding-window quadratic regression method $(S Q R M)$. In this technique, the quadratic regression is fit to the first subsample (a window with duration, $\tau)$ of a record, and the resulting acceleration estimate is attributed to the central time of the window, $t_{c}$. The regression window is then shifted by an interval of $\boldsymbol{\Delta} \boldsymbol{\tau}$ (which does not necessarily correspond to the analysis window, $\boldsymbol{\tau}$ ), and the analysis is repeated, creating a time series of average accelerations.

$$
S L(t, \tau)=a+b t+c t^{2}+\varepsilon(t)
$$

resulting in

$$
A_{S Q R M}\left(t_{c}, \tau\right)=2 c\left(t_{c}, \tau\right)
$$

Each regression window covers a complete time period of $\tau$; therefore, the maximum value of $t$ c is the length of the time series minus $\boldsymbol{\tau} / 2$. This analysis can be repeated for a series of $\boldsymbol{\tau}$ values. As will be shown later, increasing $\tau$ has the effect of damping high frequency signals in $A_{S Q R M}\left(t_{c}, \tau\right)$.

It is suggested that an alternative calculation informed by the observations that, over time scales of order decades, many $S L$ records appear to be composed of linear segments with varying slopes and durations rather than a single or series of quadratic forms; in other words, the accuracy of the regression is improved through discontinuous piecewise or segmented linear regression (Woodworth, 1990; Church and White, 2006; Merrifield and others, 2009; Woodworth and others, 2009; Woodworth and others, 2011; Sallenger and others, 2012). A rate-based method (RBM) is used to calculate a time series of average accelerations by differencing successive estimates of the rate of sea-level rise

$$
A_{R B M}\left(t_{c}, \tau\right)=\frac{2 \operatorname{SLRD}\left(t_{c}, \tau\right)}{\tau}
$$

with the sea-level rate difference ( $S L R D$ ) between the two sub-intervals given by

$$
\operatorname{SLRD}\left(t_{c}, \tau\right)=\beta_{2}\left(t_{2}, \frac{\tau}{2}\right)-\beta_{1}\left(t_{1}, \frac{\tau}{2}\right)
$$

where $t_{1}$ and $t_{2}$ are the start times of the first and second halves of a total regression interval with dura- 
tion $\tau$. Here $\tau$ is the combined time interval of two separate regresssions rather than the interval for one regression, and $t_{c}$, the central time of the estimate, is taken as $t_{2}$, the first date of the latter regression interval. The two underlying regression models are

$$
\begin{aligned}
& S L\left(t\left(t_{1}, \frac{\tau}{2}\right)\right)=\alpha_{1}+\beta_{1} t+\varepsilon_{1}(t) \\
& S L\left(t\left(t_{2}, \frac{\tau}{2}\right)\right)=\alpha_{2}+\beta_{2} t+\varepsilon_{2}(t)
\end{aligned}
$$

Similar to the approach demonstrated by Jevrejeva and others (2008), if the chosen $\tau$ is less than the total record length, the analysis may be repeated after shifting $t_{1}$ and $t_{2}$ by $\boldsymbol{\Delta \tau}$. The acceleration calculations may be repeated until $t_{2}+\frac{\tau}{2}$ reaches the last measurement date.

For both sliding regression methods ( $S Q R M$ and $R B M)$, if $\boldsymbol{\Delta} \boldsymbol{\tau}<\boldsymbol{\tau}$ the time-stepped regression windows overlap and it is important to remember that resulting points in the $A_{S Q R M}, A_{R B M}$, and $S L R D$ time series will not be independent because they have underlying data points in common. If additional statistical analyses are conducted using the acceleration time series, it is necessary to account for this lack of independence (see Sallenger and others (2012) for implications). If the regression step interval $(\boldsymbol{\Delta} \boldsymbol{\tau})$ corresponds to one data point, an approximation of the maximum number of strictly independent data points in the estimated acceleration time series is $(N-(\tau * \Delta \tau)) /(\tau * \Delta \tau)$, where $N$ is the number of values in the original $S L(t)$ record.

With regard to window duration $\boldsymbol{\tau}$, many investigators refer to Douglas (2001) who found that the duration needed to obtain a stable estimate of the linear rate of SLR for use in estimating the rate of global sea level rise generally is greater than 50 years and that regression results for records less than 20 years are seriously contaminated by decadal-scale fluctuations. Because many societal decisions are made on the basis of information with characteristic time scales of years to decades, specifying an optimal value for $\boldsymbol{\tau}$ should be avoided. It remains at the discretion of the user to carefully choose a range of appropriate values for $\boldsymbol{\tau}$ and $\boldsymbol{\Delta} \boldsymbol{\tau}$ on the basis of objectives, the errors of the underlying regressions, and the signal-to-noise characteristics of the time series. The use of a range of $\tau$ values that extends beyond the times scales of interest to the user would provide a context for specific conclusions.

It is important to note that specifically modeling $S L=f(t)$ is not being done in any causal sense, that is, it is understood that $S L$ is being forced by a physical process not by the passage of time. Least squares regression methods are being used as a tool to allow estimation of the second derivatives of a sea-level elevation time series (the accelerations) and to quantify the potential error of those estimates. Sophisticated filtering methods have been applied to the $S L$ time series prior to calculation of rates or accelerations using methods similar to those above, improving the fit of the regression (Jevrejeva and others, 2006; Jevrejeva and others, 2008; Hamlington and others, 2010) but potentially complicating the estimation of error. 


\section{Uncertainty Analysis}

Generalizing the regression equations 2,3 , and 7 as

$$
S L(t)=\left(\sum_{i=0}^{n} \beta_{i} t^{i}\right)+\varepsilon_{n}(t)
$$

the standard errors on the regression coefficients (assuming normally distributed residuals) are given by

$$
\sigma\left(\beta_{i}\right)=\sqrt{\frac{R S S}{N_{r}}\left(\left[\mathbf{X}^{T} \mathbf{X}\right]^{-1}\right)}
$$

where $\sigma\left(\beta_{i}\right)$ is the standard error of the ith parameter estimate $(i=j-1), R S S$ is the sum of squares of the residuals, $N_{r}$ is the number of degrees of freedom for the regression model (subject to the limits of serial correlation), $\boldsymbol{X}$ is the matrix composed of the basis functions $\left(t^{0}, t^{1}, t^{2}\right.$, and so forth) used in the regression model, and $j$ is the number of elements in X (Bendat and Piersol, 1986).

Serial correlation between points is a significant issue for the tide gage (and reconstructed global) data commonly used in $S L$ acceleration calculations. Error estimates for serial correlation are corrected by substituting an effective number of independent data points $\left(N_{e f f}\right)$ to replace $N$ in the typical representation of $N_{r}=N-j$ ( $N$ is the number of data points used in the regression model, and $j$ is the number of estimated coefficients). Maul and Martin (1993) suggest a first-level correction can be made by calculating $N_{\text {eff }}$ for annual mean sea-level measurements using the lag-1 autocorrelation, $r$ :

$$
N_{e f f}=N \frac{1-r}{1+r}
$$

With the large decadal-scale variability present in tide gage records making direct computation of $r$ an unstable estimate of the long-period variability, it is suggested to fit an autoregressive order one, AR(1), model to the residuals and use the AR(1) coefficient for $r$. Unless stated otherwise, the AR(1) technique is used in the subsequently described analysis to correct the standard error. A typical value for the AR(1) coefficient is 0.40 , decreasing $N$ by about 40 percent and increasing the standard error of the regression coefficient by about 50 percent. This increase varies and these numbers are only general approximations. This adjustment technique is standard procedure for the National Oceanic and Atmospheric Administration (NOAA) (Zervas, 2009). Foster and Rahmstorf (2011) show that the true error may be even larger if the AR(1) model underestimates the serial correlation. They present a clear discussion of a correction methodology given a generic autocorrelation structure.

The standard error of $S L R D$ in the current report is calculated as:

$$
\sigma_{S L R D}\left(t_{c}, \tau\right)=\sqrt{\sigma_{\beta_{1}}^{2}\left(t_{1}, \frac{\tau}{2}\right)+\sigma_{\beta_{2}}^{2}\left(t_{2}, \frac{\tau}{2}\right)}
$$

where the standard errors of the coefficients for the two regression windows $\left(\sigma_{\beta_{1},}^{2}\right.$ and $\left.\sigma_{\beta_{2}}^{2}\right)$ are the

adjusted values calculated using equations 9 and 10 . The standard errors reported for $A_{Q R M}$ and $A_{S Q R M}$ are adjusted for serial correlation using equations 9 and 10. These calculated errors are compared to error estimates derived from Monte Carlo simulations discussed in a later section. 


\section{Simple Examples}

The sensitivities and performance of the three methods were examined using three sets of synthetic time series, each representing annual mean sea level over 201 years (nominally 1850-2050 for plotting purposes). The first set is composed of three time series, satisfying the $Q R M$ assumption of constant acceleration: TS1, a constant linear trend; TS2, defined by constant acceleration with no linear trend; and TS3, constant acceleration added to a linear trend (table 1). The $Q R M$ was applied using the entire time series with $t=0$ set at year 1850, giving an $A_{Q R M}$ estimate applicable to all years (1850-2050). For $A_{S Q R M}\left(t_{c}, \boldsymbol{\tau}\right)$ and $A_{R B M}\left(t_{c}, \boldsymbol{\tau}\right) \boldsymbol{\tau}=60$ years and $\boldsymbol{\Delta} \boldsymbol{\tau}=1$ year are fixed for demonstration purposes, resulting in calculated acceleration time series from $t_{c}=1880$ to $t_{c}=2021$. Each regression sets $t=0$ at the first year in the window. This does not effect acceleration values but does result in more intuitively meaningful rate calculations in the cases where $t^{2}$ coefficients are calculated. As expected for these three very simple time series, all techniques accurately estimated the known accelerations (fig. 1).

Table 1. Definitions for synthetic time series (plotted year $=t+1850)$.

\begin{aligned} & \hline Time series definitions Time vectors \\ &$T S S 1=[2 t t=0 \rightarrow 200 \\ & T S 2=\left[0.01 t^{2}\right. t=0 \rightarrow 200 \\ & T S 3=\left[2 t+0.005 t^{2}\right. t=0 \rightarrow 200 \\ & T S 4=\left[\begin{array}{ll}2 t & t=0 \rightarrow t_{s} \\ 2 t+0.005 t^{2} & t=\left(t_{s}+1\right) \rightarrow 200 \\ & t_{s}=0 \rightarrow 199 \\ 2 t & t=0 \rightarrow t_{s} \\ 4 t & t=\left(t_{s}+1\right) \rightarrow 200 \\ & t_{s}=0 \rightarrow 199\end{array}\right.\end{aligned}$

TS4 and TS5 (set 2) demonstrate how each technique handles very simple violations of the assumption of constant acceleration within a regression interval (fig. 2). Either (1) the year at which the otherwise constant acceleration increases from 0 to 0.01 (the TS4 variants) or (2) the year the linear rate of $S L R$ increases from $2 \mathrm{~mm} / \mathrm{yr}$ to $4 \mathrm{~mm} / \mathrm{yr}$ (the TS5 variants) was varied. The subscripted year indicates the time $\left(t_{s}\right)$ when there was a change in the acceleration.

Each variant time series results in predictions of $A_{Q R M}, A_{S O R M}$, and $A_{R B M}$ (or $S L R D$ ). Results for the variants with acceleration steps at the midpoint year $t_{s}=1950$ demonstrate some of the differences between these calculations (fig. 3). $A_{S L}(t)$ for the TS4 variants is characterized by a step function with an increase in acceleration from 0 to 0.01 (at year 1950 for the variant shown) and for the TS5 variants by a finite amplitude impulse function at the year when the rate increase occurs. $A_{Q R M}$ represents both TS4 and TS5 accelerations with constant values that represent the best leastsquares fit to the entire respective $S L$ time series. The $A_{S Q R M}\left(t_{c}, 60\right)$ and $A_{R B M}\left(t_{c}, 60\right)$ estimates are smoothed representations of the true accelerations and give the appearance of a weighted moving average filter having been applied to the 

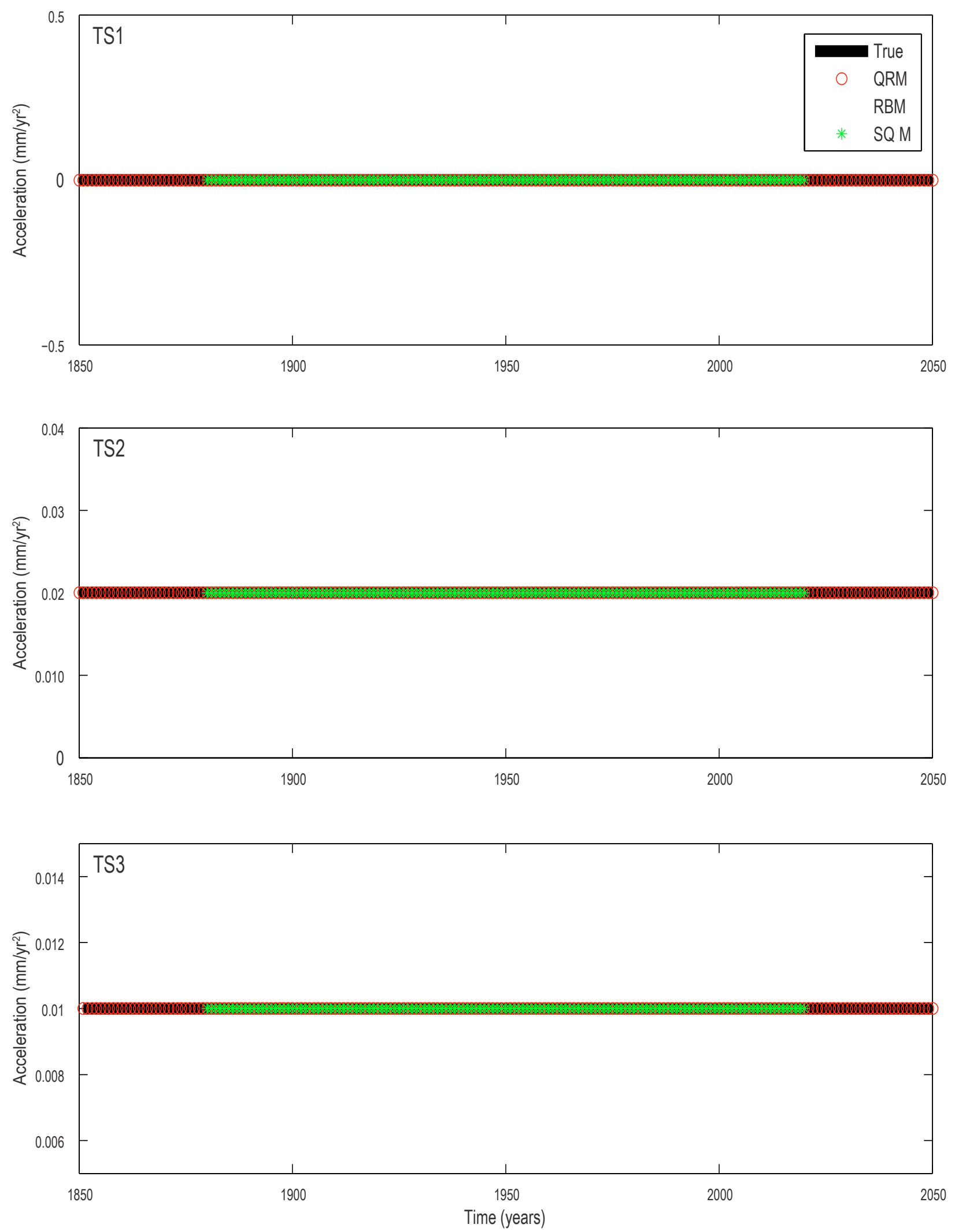

Figure 1. Acceleration estimates for TS1, TS2, and TS3. These times series meet the $A_{\text {SQRM }}$ assumption of constant acceleration throughout the duration of the record. [mm/ $/ \mathrm{yr}^{2}$, millimeters per year squared] 
true $A_{S L}(t)$ time series. The smoothing-related bias extends $\tau / 2$ on either side of $t_{s}$. The $A_{S Q R M}\left(t_{c}, 60\right)$ and $A_{R B M}(t, 60)$ estimates correctly define $A_{S L}(t)$ outside this smoothing region for the TS4 and TS5 variants. The results for individual variants can be rotated and stacked to show the temporal evolution of the estimates as $t$ is incremented (figs. 4, 5). The horizontal axes are the year the nonzero acceleration is initiated; each year represents a different time series variant. The vertical axes are the years for which acceleration is either known ( $t$, figs. 4a, 5a) or estimated ( $t$, figs. $4 \mathrm{~b}, 4 \mathrm{c}, 4 \mathrm{~d} ; 5 \mathrm{~b}, 5 \mathrm{c}, 5 \mathrm{~d})$. The $A_{\text {ORM }}$ results for both variant sets (figs. $4 \mathrm{~b}, 5 \mathrm{~b}$ ) are biased over a large range of the prediction space. A particular concern is the inability of this method to correctly capture the temporal evolution of acceleration. In light of the recent interpretations of Houston and Dean (2011a) and Watson (2011) in their studies of average acceleration, $A_{O R M}$, the increasing underprediction of the magnitude of recent acceleration as the change in acceleration moves toward the present is particularly noteworthy. Stated more explicitly, the combination of long records and use of a single-fit quadratic equation to test for, or to represent, recently changed acceleration is likely to result in statistically valid but misleading results.

The $A_{R B M}\left(t_{c}, 60\right)$ and $A_{S Q R M}\left(t_{c}, 60\right)$ estimates produce less overall bias and limit the distortion of the temporal evolution of acceleration patterns (figs. 4c, 4d; 5c, 5d) but do smooth the abrupt transitions of the true values. The $A_{R B M}\left(t_{c}, 60\right)$ and $A_{S Q R M}\left(t_{c}, 60\right)$ estimates also suffer from blanking of duration $\tau / 2$ at both the beginning and end of the available record, although this effect could be lessened by using increasingly smaller values of $\tau$ at the beginning and end of the record.
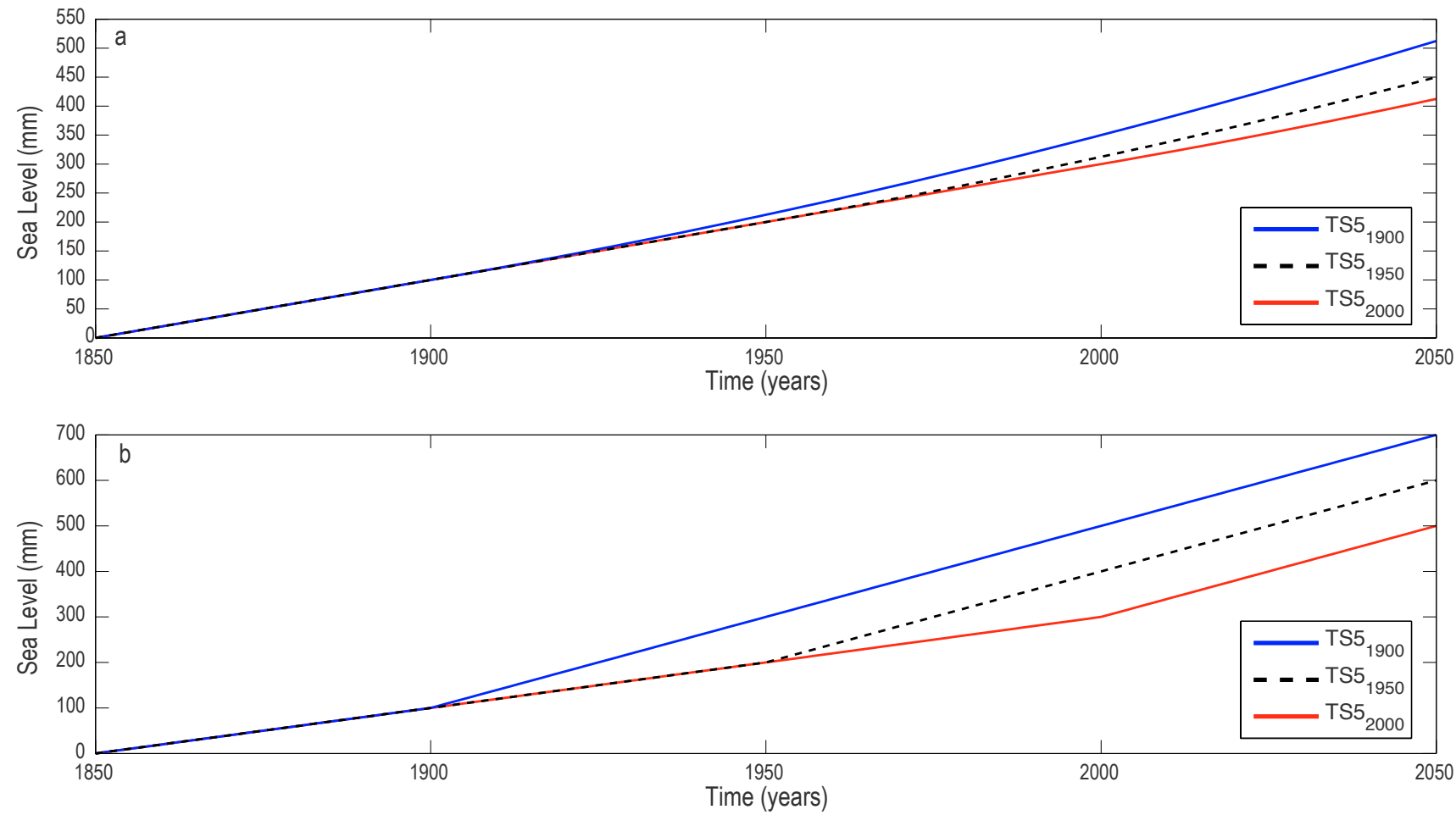

Figure 2. Examples of TS4 and TS5 variants. (a) TS4, where the start year of a constant acceleration within the time series is initiated. (b) TS5, where the start year of an increased rate of $S L$ rise is initiated. [mm, millimeter] 


\section{Bias of Acceleration Estimates for TS4 and TS5 Variants}

The TS4 variant bias errors for both sets of acceleration estimates, although generally small compared to the magnitude of the accelerations, can reach the magnitude of the known accelerations for some regions of the prediction space. The map of $Q R M$ bias is relatively complex (fig. 6a), and the magnitudes are generally larger than those for $R B M$ estimates (fig. $6 \mathrm{c}$ ). This latter point is particularly true for the estimates of acceleration in the years immediately prior to an acceleration with a start year near the beginning of the record (acceleration is overestimated) and for the years immediately after an acceleration with a start year late in the record (acceleration is underestimated). The $A_{R B M}$ biases are generally smaller in magnitude and are confined to the narrow region where the start year of the quadratic term falls within the total regression window of duration $\tau$. The $A_{S Q R M}$ bias errors have the same pattern as the $A_{R B M}$ biases. For a given $t_{c}$, the width of the biased region is $\boldsymbol{\tau}$ (fig. 3 ).

The $A_{Q R M}$ biases for TS5 variants are also generally larger and more widespread than the biases of $A_{R B M}$ estimates (fig. $6 \mathrm{~b}, 6 \mathrm{~d}$ ). The $A_{R B M}$ biases are again confined to a band of width $\tau$ that surrounds the diagonal, marking when the abrupt change in rate occurs. Because both techniques introduce temporal averaging of conditions over the lengths of their respective regression windows, both techniques have issues defining the true signal that, for any one variant, has the entire non-zero acceleration contained within 1 year. For the $A_{R B M}$ estimate, reducing the window width $\tau$ will decrease the bias (eq. 5) but, in the presence of noise, may result in unacceptably large confidence intervals about the estimate. The $A_{S Q R M}$ bias errors mirror the bias pattern of the $A_{R B M}$ estimates (fig. 6f).
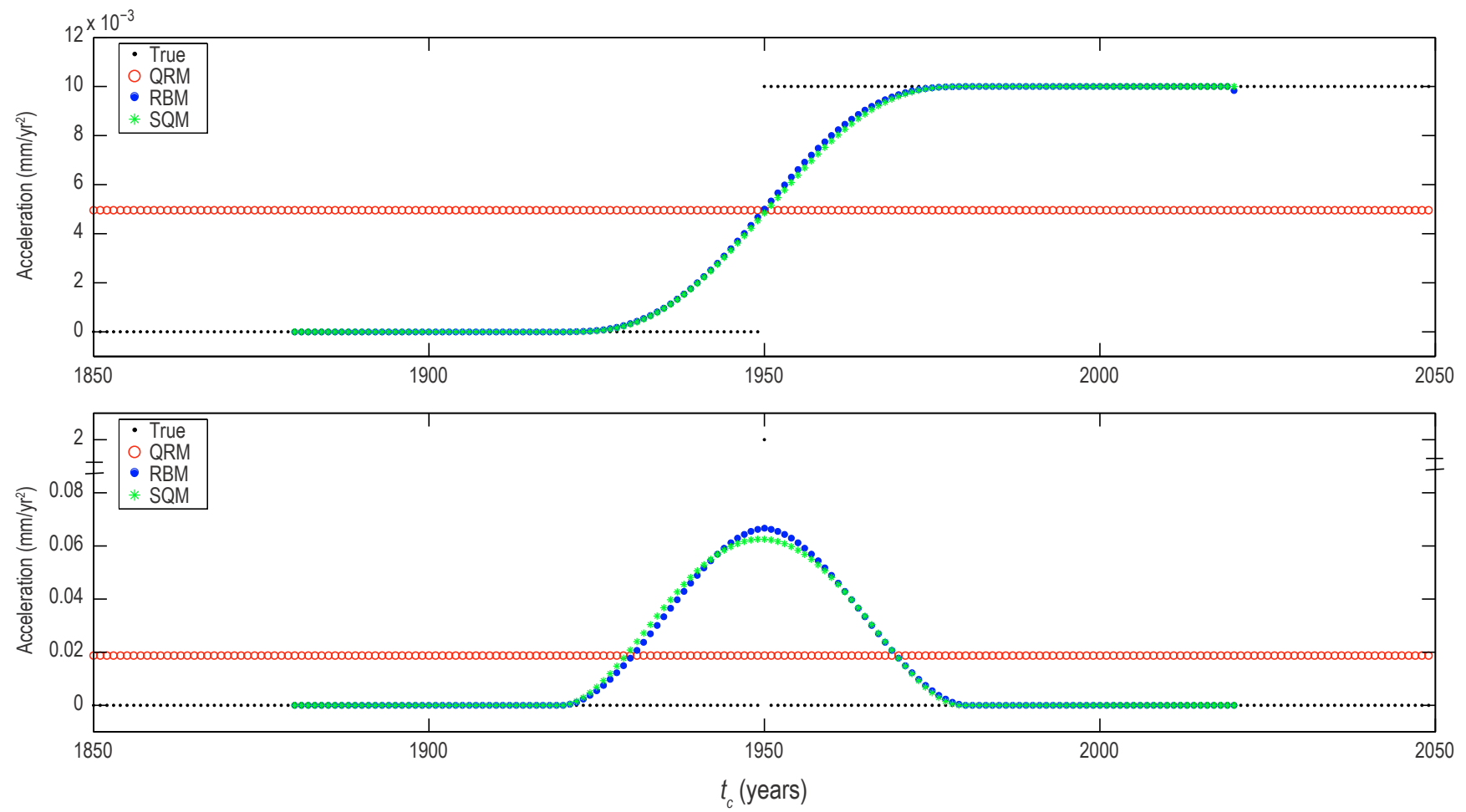

Figure 3. Acceleration estimates for TS4 ${ }_{1950}$ (top) and TS5 ${ }_{1950}$ (bottom) using the three regression-based estimators. The total duration of the smoothing interval for $A_{\text {SQRM }}\left(t_{c}, 60\right)$ and $A_{R B M}\left(t_{c}, 60\right)$ is equal to the duration of the window, 60 years for this example. [mm/yr², millimeters per year squared] 

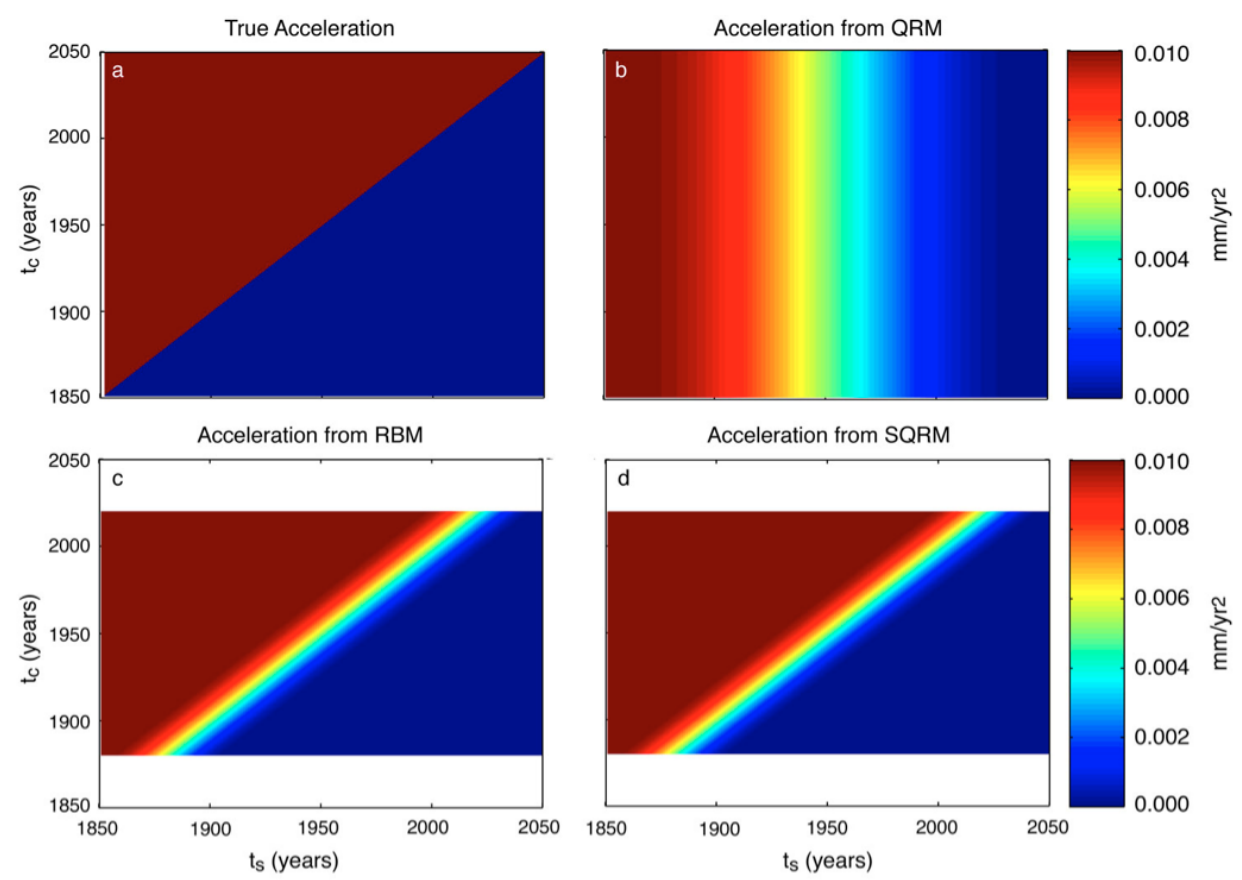

Figure 4. True and predicted $A_{S L}(t)$ for the TS4 variants. The vertical axis corresponds to the year associated with the acceleration estimate (or simply the year in (a)), and the horizontal axis increments through the TS4 variants. (a) True acceleration, $0.01 \mathrm{~mm} / \mathrm{yr}^{2}$ for $t$ greater than or equal to $t_{s}$ and otherwise 0. (b) $A_{Q R M^{*}}$ (c) $A_{R B M^{*}}$ (d) $A_{S Q R M^{*}}$ $\left[\mathrm{mm} / \mathrm{yr}^{2}\right.$, millimeters per year squared]
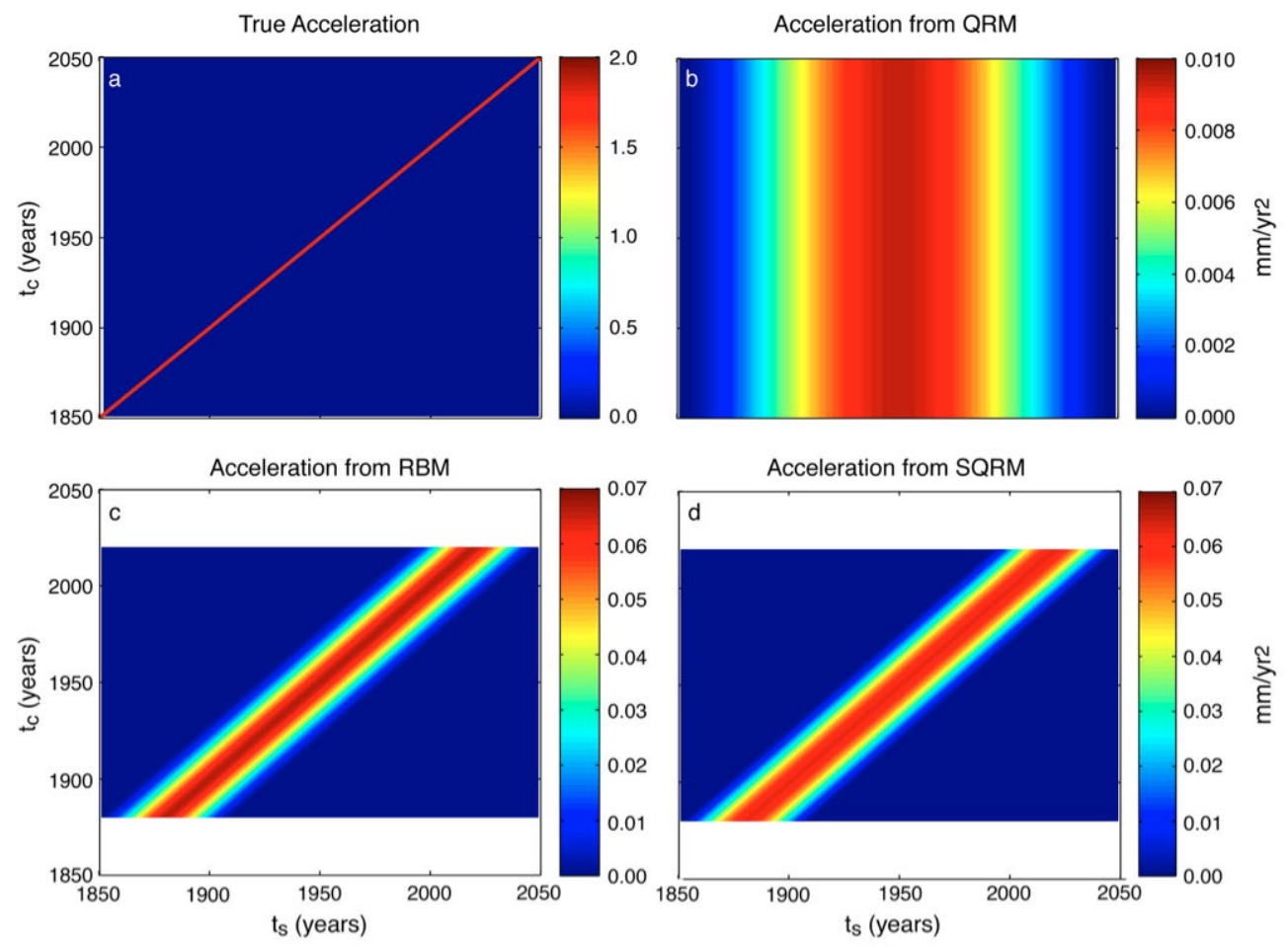

Figure 5. True and predicted $A_{S L}(t)$ for the TS5 variants. The vertical axis is $t_{c}$, the year associated with the acceleration estimate (or simply the year in (a)), and the horizontal axis increments through the TS5 variants. (a) True acceleration, 0 everywhere except on a line defined by $t=t_{s}$ where it is $2 \mathrm{~mm} / \mathrm{yr}^{2}$. (b) $A_{Q_{Q R M^{*}}}$ (c) $A_{R^{\prime} M^{*}}$ (d) $A_{S Q R M^{*}}$ $\left[\mathrm{mm} / \mathrm{yr}^{2}\right.$, millimeters per year squared] 


\section{Modes of Acceleration and SLRD Time Series.}

The shape of the $\operatorname{SLRD}\left(t_{c}, \boldsymbol{\tau}\right)$ and $A_{S Q R M}\left(t_{c}, \boldsymbol{\tau}\right)$ time series are distinctively different depending on the conceptual model for how sea-level acceleration may be occurring (fig. 7). In the following sections, focus will switch from estimating acceleration (A) to piecewise rate differences (SLRD). The estimates for a constant acceleration (that is, TS2, a fixed quadratic coefficient) result in a constant value for the time series (figs. 7b, 7c). A change in an otherwise constant acceleration, as in TS4 ${ }_{1950}$ where the quadratic coefficient increases from 0 to 0.005 (acceleration from 0 to 0.01 , eq. 1), produces time series with two segments of constant rate change connected by a smooth transition region of width $\boldsymbol{\tau}$. A change in otherwise constant linear rate, as given by TS5 ${ }_{1950}$ (rate increase from 2 to $4 \mathrm{~mm} / \mathrm{yr}$ at year 1950), produces a "bump" of width $\tau$. The distinctive differences might be used, in combination with varying $\tau$, to grossly characterize the mode of $S L$ response and narrow the estimate of when the acceleration occurred or changed, assuming the possibility of discrete changes in $S L$ response to external forcing.

It is important to note in figure $7 \mathrm{~h}$ that the $S L R D$ peak estimate matches the magnitude of the rate change at the year of the change. If one accepts the "model" of changing rates of $S L R$ occurring in discrete steps (opposed to smooth quadratic segments), it would be preferable to use the $\operatorname{SLRD}\left(t_{c}, \boldsymbol{\tau}\right)$ representation of rate change.
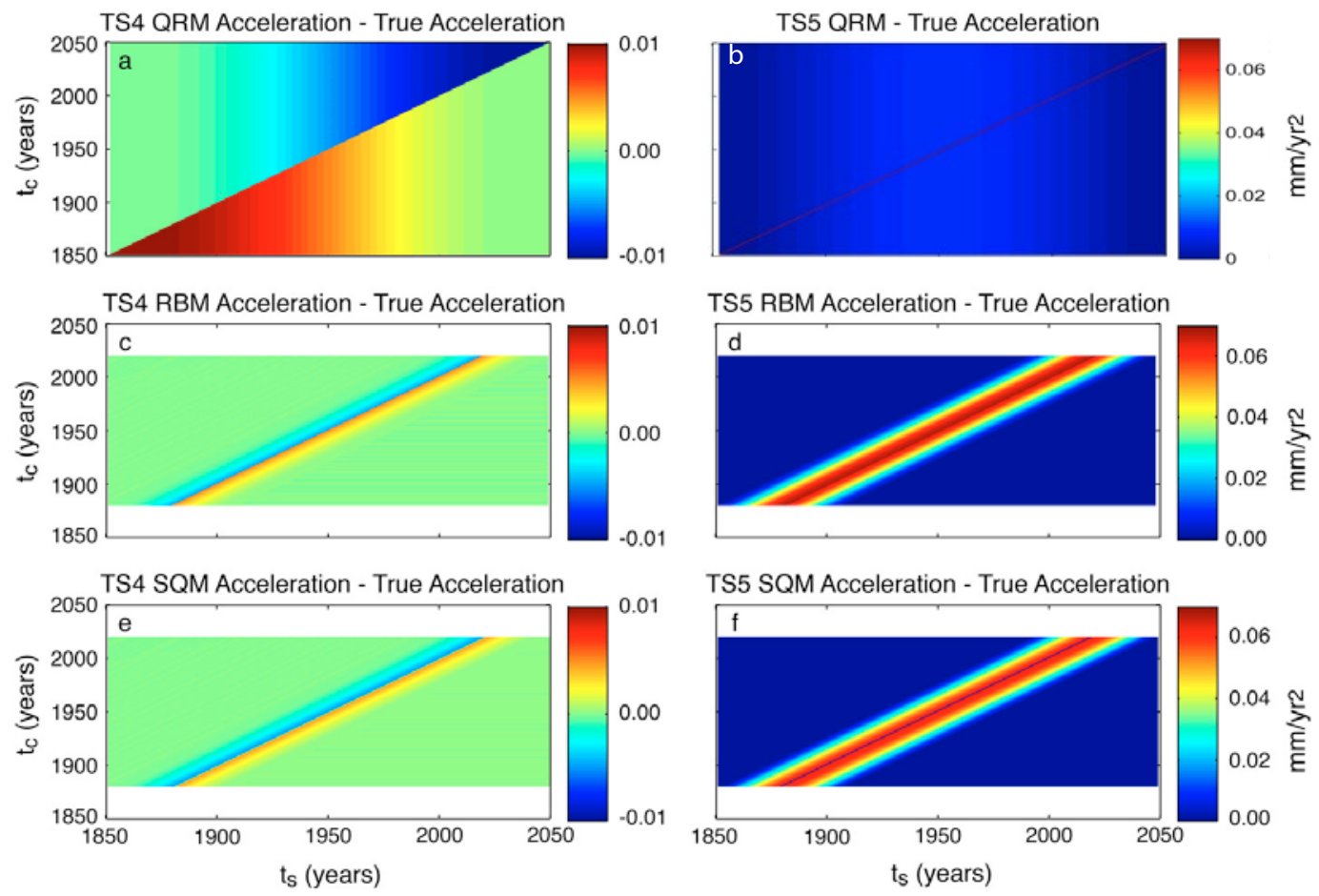

Figure 6. Bias for the three estimates of $A_{S L}(t)$ for the TS4 and TS5 time series variants. The vertical axis corresponds to the year associated with the acceleration estimate, and the horizontal axis increments through the variants as the year of the change in acceleration $\left(t_{s}\right)$ moves through the record. The colors represent the difference between the true values and the predictions given by $A_{Q R M}$ (top row), $A_{R B M}$ (middle row), and $A_{S Q R M}$ (bottom row) for TS4 (left column) and TS5 (right column). [mm/yr², millimeters per year squared] 


\section{Monte Carlo Error Analysis for Estimates of $\operatorname{SLRD}\left(t_{c}, \tau\right)$}

The accuracy and bias of SLRD estimates in the presence of noise were investigated through Monte Carlo simulations (number of simulations $=10^{4}$ ) using TS4 ${ }_{1950}$ and TS5 ${ }_{1950}$ (fig. 8). Realizations of noise, with varying characteristics, both of the statistical formulation and the magnitude of variance, are added to each time series. Three noise types were simulated, $\mathrm{f}^{-0.6}$ red noise (where $\mathrm{f}$ is the frequency, $\operatorname{AR}(1)$ noise ( $\rho=0.4$, where $\rho$ is the AR(1) coefficient), and white (Gaussian) noise. In the cases of the red and AR(1) noise, parameters were fit to the spectrum of annual residuals (linear term only) from 28 tide gages along the Atlantic coast of North America with records beginning in 1970 or earlier. Tide gage data were obtained from the Permanent Service for Mean Sea Level (http://www.psmsl.org/data/ obtaining/complete.php).The median value from each parameter fit was chosen for the Monte Carlo simulations. The noise variance magnitudes were based on the variance of residuals from the same gages (approximately 2,500 square millimeters $\left.\left(\mathrm{mm}^{2}\right)\right)$. For each noise type, three variance levels $(1,250$; 2,500; and 3,750 $\mathrm{mm}^{2}$; that is, 50,100 and 150 percent of observed, respectively) were tested.

Examples of $T S 5_{1950}$ with the different noise types (at the 100 percent variance level), the ensemble mean of the estimated $\operatorname{SLRD}\left(t_{c}, 60\right)$ time series, and the distributions of the $10^{4}$ estimated $S L R D$ at $t_{c}$ $=1950$ are shown in figure 9. Although the type of noise has no effect on the bias of the technique at the year of the rate shift (it is 0 at 1950 for all noise types), it does dramatically influence the distribution of the estimates for any $t_{c}$. Red noise introduces variability at periods of approximately $\mathrm{O}(\boldsymbol{\tau})$, which is identified by the analysis as a signal in SLRD, resulting in the widest distribution of SLRD values. White noise, with no long period bias in noise distribution, produces the narrowest distribution of predicted $S L R D$. A set of probability density funtions (PDF) from TS4 ${ }_{1950}$ and $\mathrm{TS}_{1950}$ shows the $S L R D$ method produces unbiased estimates of the expected value regardless of noise formulation or magnitude (fig. 10; table 2). As expected, the variance of $S L R D$ predictions increases with increasing noise variance. The same trends (increasing variance with increasing noise and the relative shape of the noise PDFs with dif-
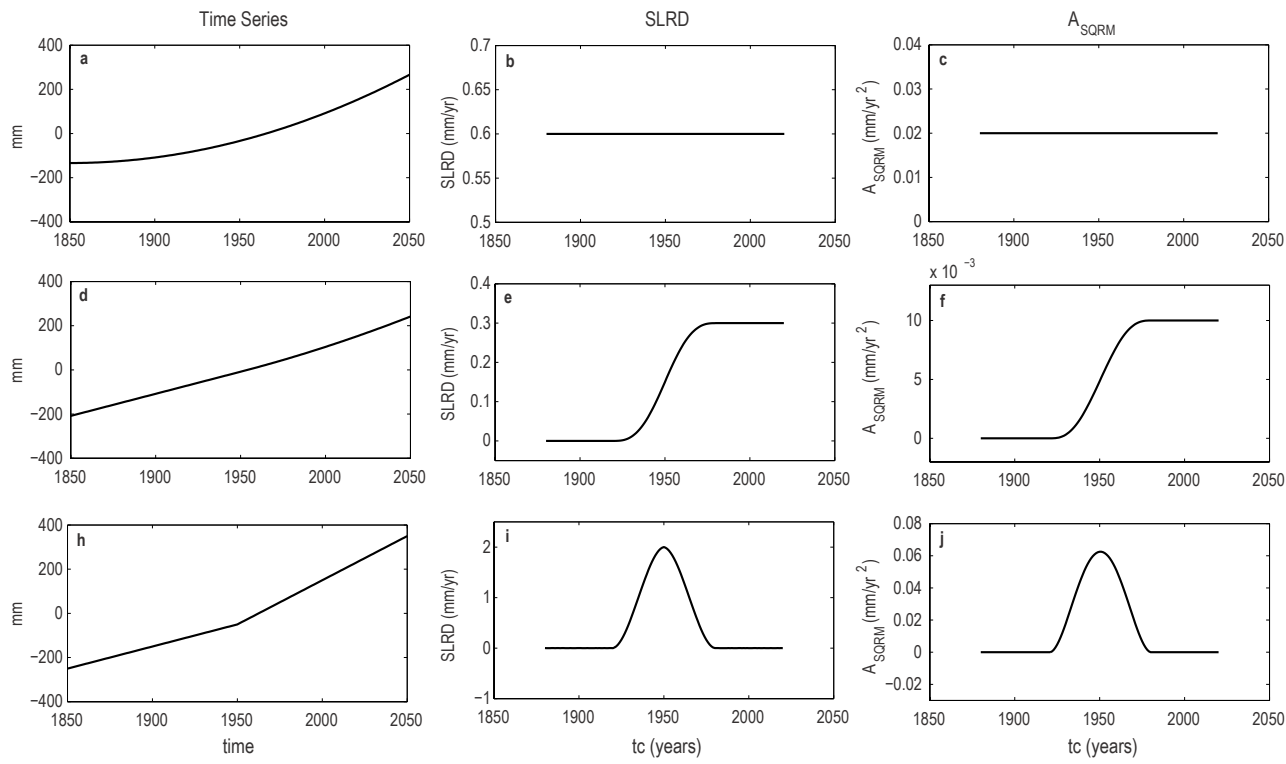

Figure 7. Time series representations of three simple acceleration patterns as shown by SLRD and $A_{\text {SQRM }}$. Top row (a-c): Constant acceleration of $0.02 \mathrm{~mm} / \mathrm{yr}^{2}$. Middle row (d-f): Increase in acceleration from 0 to $0.01 \mathrm{~mm} / \mathrm{yr}^{2}$ at year 1950. Bottom row (g-i): Increase in otherwise constant rate from 2 to $4 \mathrm{~mm} / \mathrm{yr}$ at year 1950. [mm/ $\mathrm{yr}^{2}$, millimeters per year squared] 
ferent types of noise) are obtained for $A_{R B M}(1950,60)$ and $A_{S Q R M}(1950,60)$ and for the equivalent analyses using TS4 ${ }_{1950}$. The variation in the width of the SLRD PDF with noise at various frequency distributions demonstrates why an adjustment is required to the confidence limits on ordinary least-squares regression coefficients when serial correlation between residuals is present. Shortening the length of the regression window, $\boldsymbol{\tau}$, widens the distribution of estimated SLRD, but introduces no bias (fig. 11).

Compilations of the Monte Carlo simulations for TS4 ${ }_{1950}$ and TS5 ${ }_{1950}$ demonstrate the sensitivities of the estimates and their $1 \sigma$ errors resulting from the addition of three types of random noise with variance 2,500 $\mathrm{mm}^{2}$ (table 2). In each case the estimate is for year 1950 and the regression window is 60 years in duration, centered on 1950 . The mean values for each calculation method $\left(A_{S Q R M}, S L R D\right)$ are relatively insensitive to the the type of noise introduced; what variation exists is the result of the different degrees of low frequency contamination depending on the noise distribution. Also, it is important to note that the errors adjusted for serial correlation for red and AR(1) noise always exceed the standard calculation, and the Monte Carlo estimate of the error is the largest in all cases. In a few cases the calculated adjustment fitting an AR(1) model with white noise resulted in negative lag 1 autocorrelation estimates, thus resulting in a smaller adjusted error than the standard. The implication is the non-physical result of having more degrees of freedom than data points in the regression. In these cases, the adjusted error was set equal to the standard error. Tide gage records are autocorrelated, with various interannual, decadal, and multi-decadal signals present, so this likely would not occur in real data.
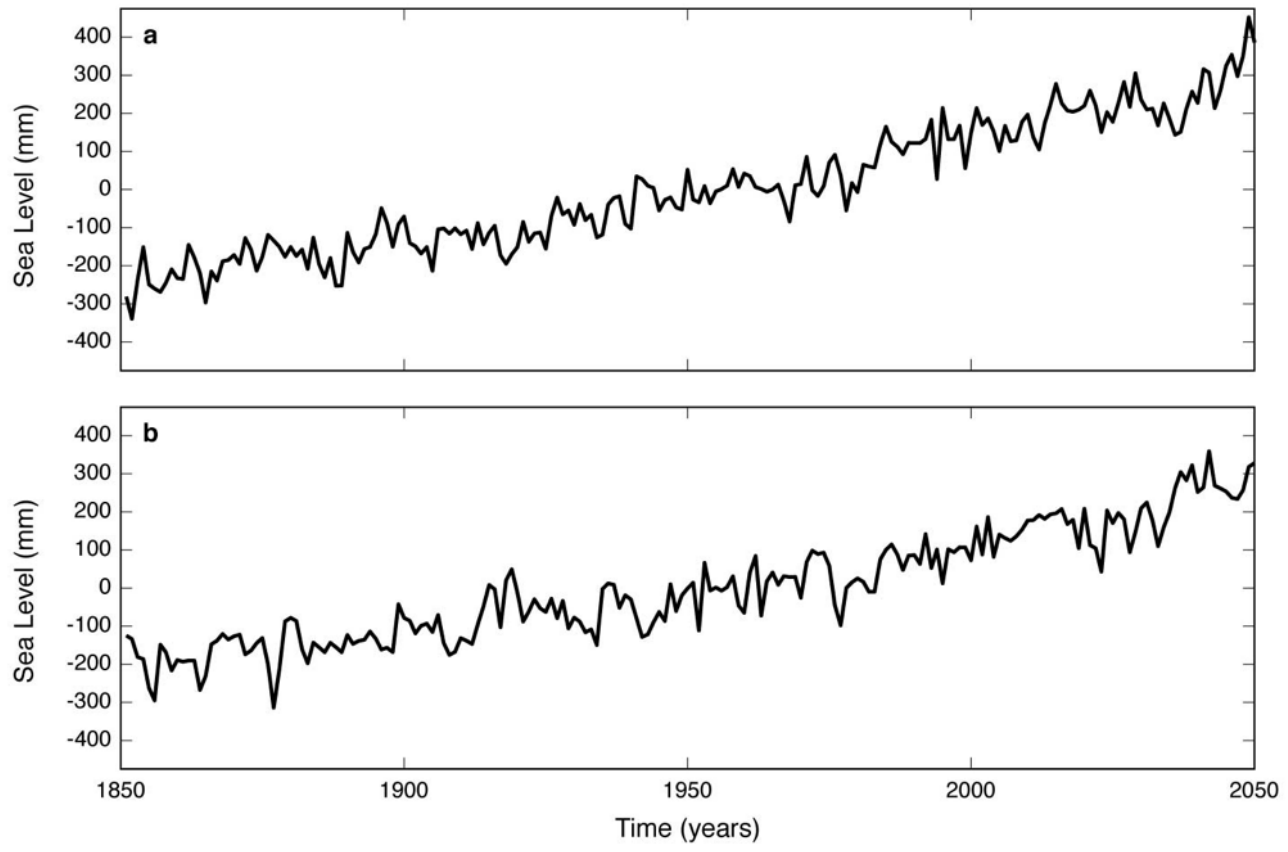

Figure 8. Examples of time series with added $A R(1)$ noise at a variance level $\left(2,500 \mathrm{~mm}^{2}\right)$ representative of U.S. east coast tide gages. (a) TS4 ${ }_{1950^{\circ}}$ (b) TS5 ${ }_{1950^{\circ}}$. $\left[\mathrm{mm}\right.$, millimeters; $\mathrm{mm}^{2}$, square millimeters] 

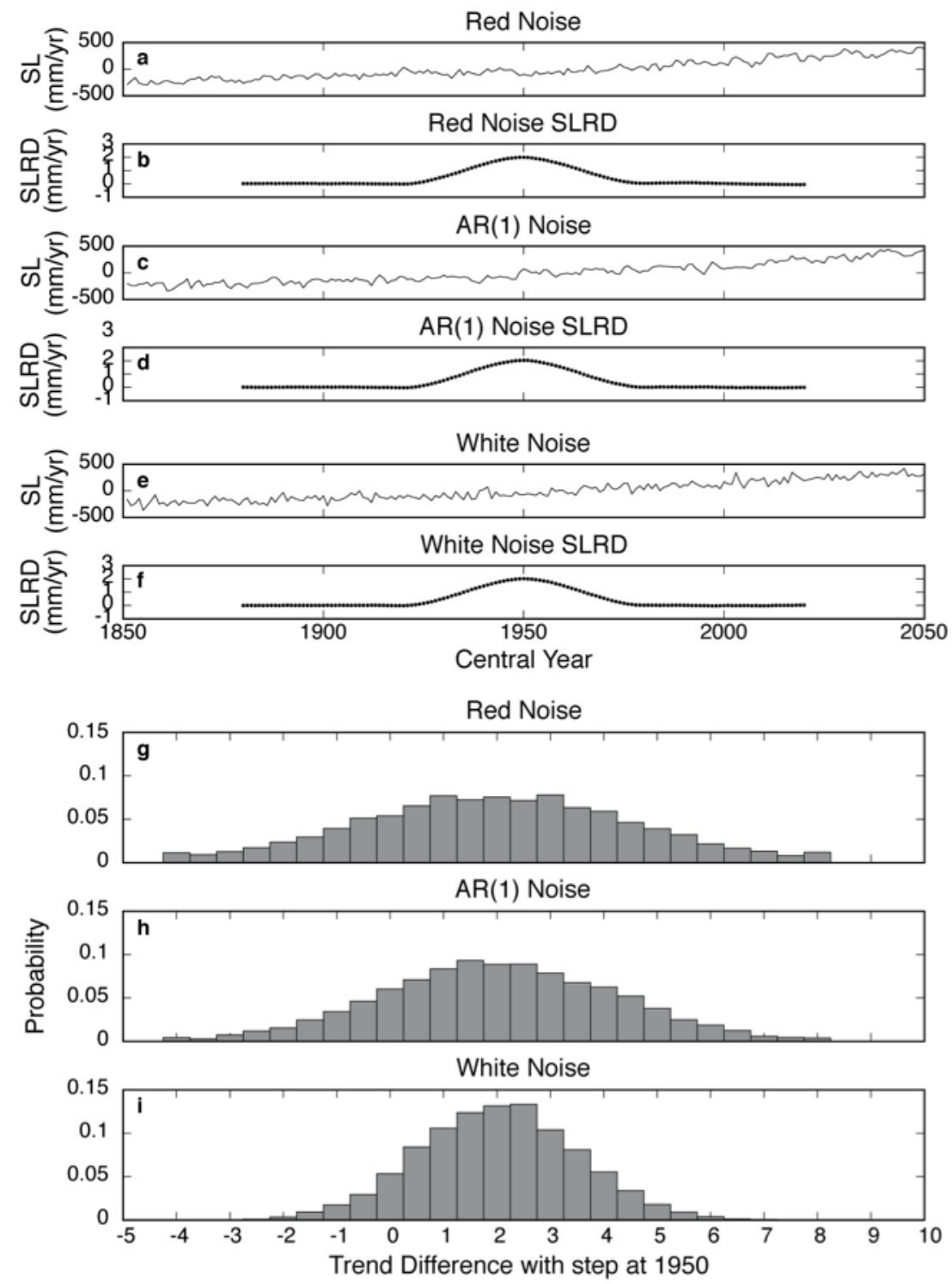

Figure 9. Summary of Monte Carlo simulation for $\operatorname{SLRD}(1950,60)$, using different noise formulations with equal variance in conjunction with $\mathrm{TS}_{1950}$. The true value for the rate increase is 2. (a) Example time series with red noise ( $\left.f^{-0.6}\right)$; (b) Ensemble mean red noise SLRD time series with $\tau=60$ years; (c) Example time series with $\operatorname{AR}(1)$ $\rho=0.4$ noise; (d) Ensemble mean AR(1) noise SLRD time series with $\tau=60$ years; (e) Example time series with white noise; (f) Ensemble mean white noise SLRD time series with $\tau=60$ years; (g) PDF of the SLRD estimates for year 1950 for red noise time series; (h) PDF of the SLRD estimates for year 1950 for AR(1) noise time series; (i) PDF of the SLRD estimates for year 1950 for white noise time series. [mm/yr, millimeters per year] 

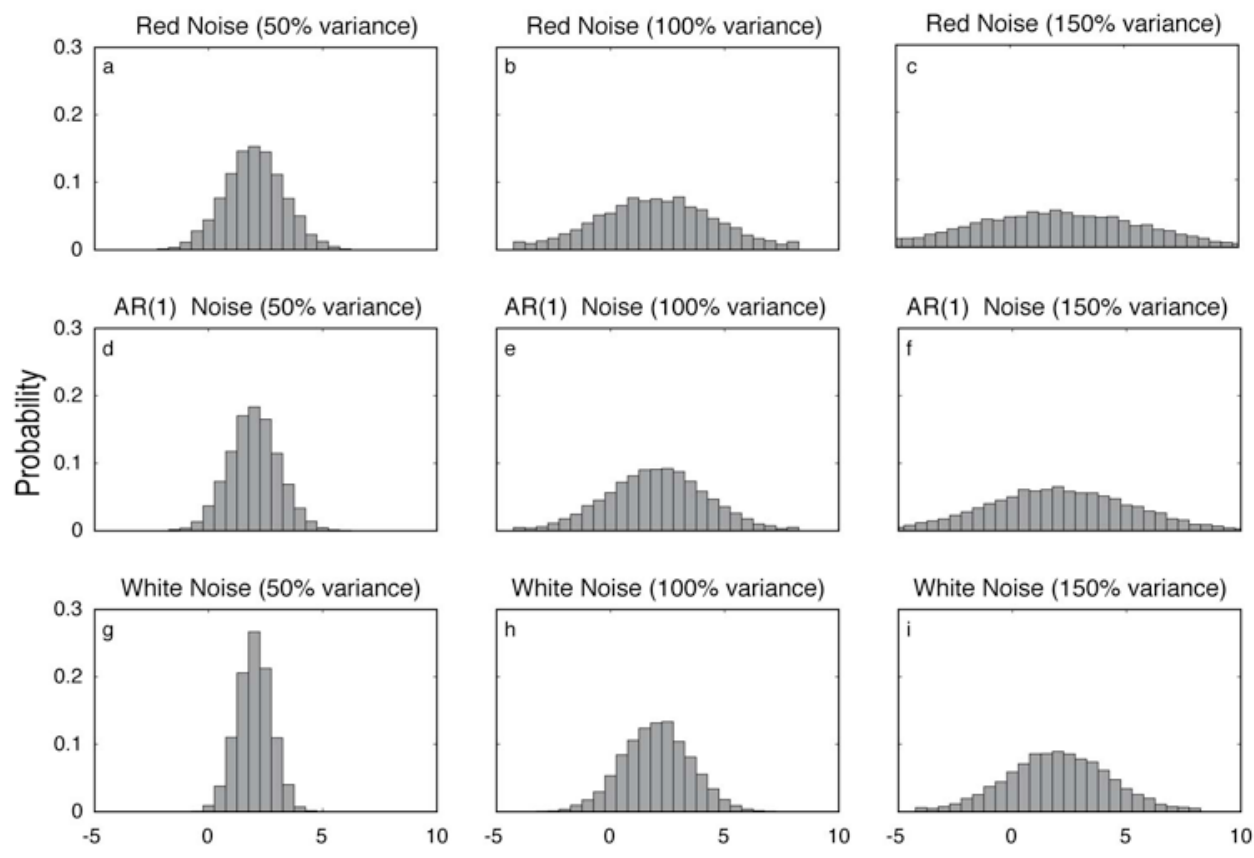

Trend difference with step at 1950 ( $\mathrm{mm} / \mathrm{yr})$

Figure 10. Summary probability distributions for the $10^{4}$ Monte Carlo predictions of $\operatorname{SLRD}(1950,60)$ for three noise types and three variance levels added to TS5 ${ }_{1950^{\circ}}$ (a) Red noise with variance $50 \%$ of observed; (b) Red noise with variance $100 \%$ of observed; (c) Red noise with variance $150 \%$ of observed; (d) AR(1) noise with variance $50 \%$ of observed; (e) AR(1) noise with variance $100 \%$ of observed; (f) AR(1) noise with variance $150 \%$ of observed; (g) White noise with variance $50 \%$ of observed; (h) White noise with variance $100 \%$ of observed; (i) White noise with variance $150 \%$ of observed. [mm/yr, millimeters per year]

Table 2. Mean acceleration/SLRD estimates with $2 \sigma$ errors on the basis of 10,000 trials. "Adjusted" indicates that the standard error has been corrected for serial correlation as described in the section "Uncertainty Analysis". [mm/yr, millimeters per year]

\begin{tabular}{|c|c|c|c|}
\hline TS4 $(1950,60)$ & Red noise (100\%) (mm/yr) & AR(1) noise $(100 \%)(\mathrm{mm} / \mathrm{yr})$ & White noise $(100 \%)(\mathrm{mm} / \mathrm{yr})$ \\
\hline$A_{S Q R M}:$ standard & $0.003 \pm 0.014$ & $0.003 \pm 0.015$ & $0.003 \pm 0.016$ \\
\hline$A_{S Q R M}:$ adjusted & $0.003 \pm 0.019$ & $0.003 \pm 0.021$ & $0.003 \pm 0.016$ \\
\hline$A_{\text {SQRM }}:$ Monte Carlo & $0.003 \pm 0.041$ & $0.003 \pm 0.036$ & $0.003 \pm 0.024$ \\
\hline SLRD: standard & $0.163 \pm 1.28$ & $0.130 \pm 1.35$ & $0.172 \pm 1.41$ \\
\hline$S L R D:$ adjusted & $0.163 \pm 1.64$ & $0.130 \pm 1.89$ & $0.172 \pm 1.41$ \\
\hline SLRD: Monte Carlo & $0.163 \pm 2.60$ & $0.130 \pm 2.16$ & $0.172 \pm 1.45$ \\
\hline TS5 $(1950,60)$ & Red noise $(100 \%)$ & AR(1) noise (100\%) & White noise $(100 \%)$ \\
\hline$A_{S Q R M}:$ standard & $0.031 \pm 0.014$ & $0.031 \pm 0.015$ & $0.031 \pm 0.016$ \\
\hline$A_{S Q R M}:$ adjusted & $0.031 \pm 0.019$ & $0.031 \pm 0.021$ & $0.031 \pm 0.016$ \\
\hline$A_{S Q R M}:$ Monte Carlo & $0.031 \pm 0.041$ & $0.031 \pm 0.036$ & $0.031 \pm 0.024$ \\
\hline SLRD: standard & $1.99 \pm 1.28$ & $1.97 \pm 1.36$ & $2.00 \pm 1.41$ \\
\hline$S L R D:$ adjusted & $1.99 \pm 1.64$ & $1.97 \pm 1.89$ & $2.00 \pm 1.41$ \\
\hline SLRD: Monte Carlo & $1.99 \pm 2.62$ & $1.97 \pm 2.17$ & $2.00 \pm 1.45$ \\
\hline
\end{tabular}




\section{Signal Detection}

The $R B M$ and $S Q R M$ methods result in smoothing of the true acceleration signal and, through the regression process, suppression of "noise" at time scales significantly less than the window duration. Following Jevrejeva and others (2008), stacking the results $\left(\operatorname{SLRD}\left(t_{c}, \boldsymbol{\tau}\right), A_{R B M}\left(t_{c}, \boldsymbol{\tau}\right)\right.$ and $\left.A_{S Q R M}\left(t_{c}, \boldsymbol{\tau}\right)\right)$ to define both the temporal evolution of the $S L R D$ (or acceleration) signal and, through using variable $\tau$, a crude filtering at different time scales, provides very useful context to the interpretation of any specific $\left(t_{c}, \boldsymbol{\tau}\right)$ (fig. 12). Using the analysis of noise-free TS $5_{1950}$ shows the underlying influence of increasing $\boldsymbol{\tau}$
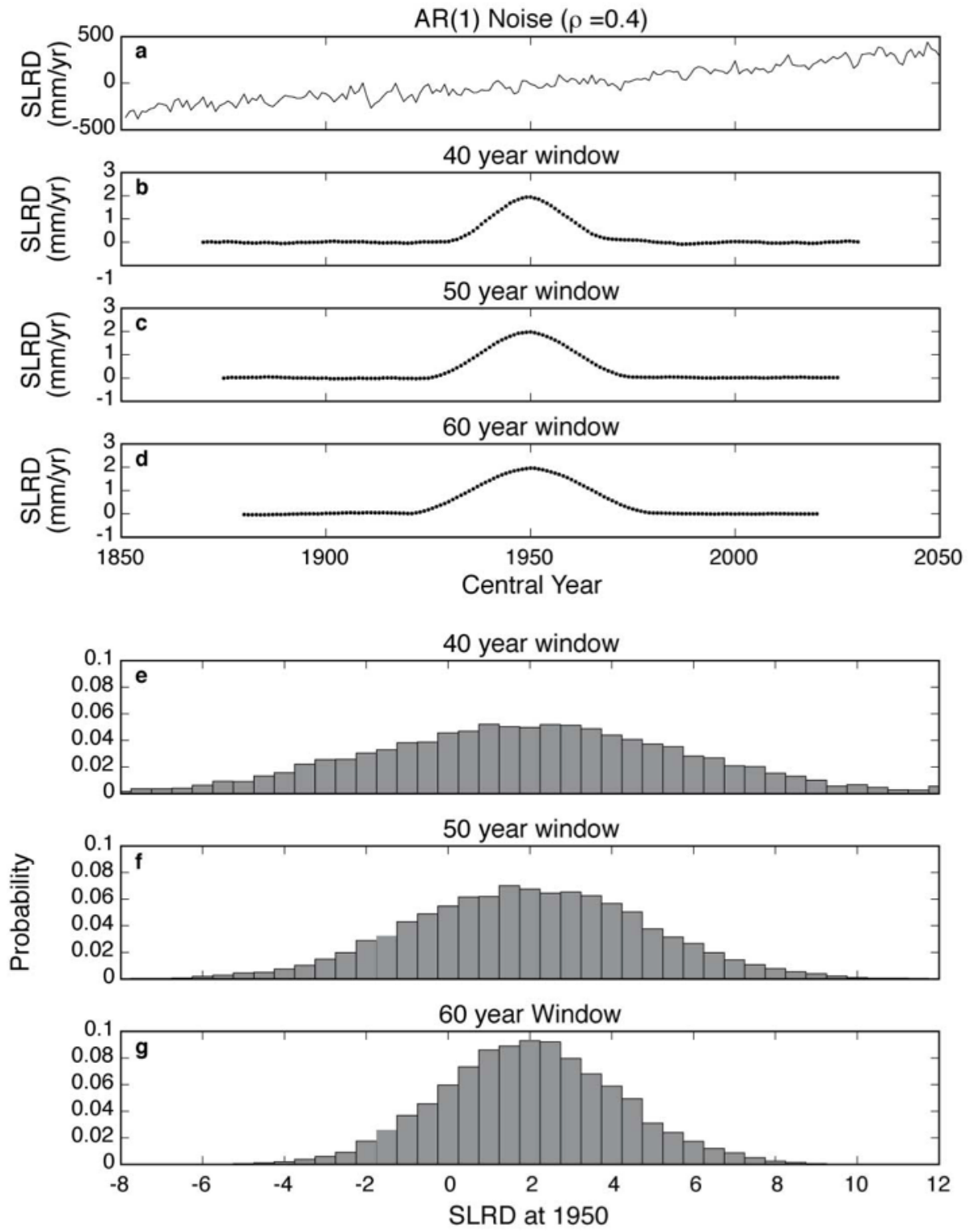

Figure 11. Effect of window duration $\tau$ on the distribution of estimated SLRD for fixed noise type and variance. (a) Example TS5 ${ }_{1950}$ variant. (b-d) Averaged $\operatorname{SLRD}(1950, \tau)$ time series from the Monte Carlo simulations for $\boldsymbol{\tau}=$ 40, 50, 60 years, respectively. (e-g) Probability density functions for predictions of $\operatorname{SLRD}(1950, \tau)$ for $\tau=40,50,60$ years, respectively. 
in smoothing the pulse of acceleration at year 1950. The region of non-zero SLRD corresponds to the spread of $\tau$-dependent bias error away from the true year of the rate increase (as shown in figure $3 \mathrm{~b}$ for $\tau=60)$.

Adding Gaussian noise to the time series creates noise in the analysis, as expected (fig. 13). As shown in figure 10, noise of any distribution type increases the random error (spread) of rate difference (or acceleration) estimates. In the case shown, interpretation of the results improves when considering analysis results across multiple values of both $t_{c}$ and $\boldsymbol{\tau}$. Given the smoothed nature of the analysis technique, it is more likely that clustered or contiguous $\left(t_{c}, \tau\right)$ cells with significant values represent signal as compared to scattered or rapidly varying $\left(t_{c}, \tau\right)$ magnitudes. Noise-related (incoherent) variability is dramatically lessened from the $\mathrm{N}=1$ case when averages are computed over $\mathrm{N}=20,100,1,000$ independent samples of the process (fig. 13b-d). For this reason, regional averaging over the largest number of available gages will eliminate random noise while the coherent signal (shown in figure 12e) survives the averaging process. These results are as expected, as shown in figure 9.

The ability to detect a significant change in the rate of SLR depends on two concepts: (1) How does the (moving, in the case of $S Q R M$ and $R B M$ ) regression window influence the representation of the magnitude of a rate increase? and (2) How do statistical uncertainties (from noise in the time series) influence the detection and significance of rate changes? These concepts are further explored using the Monte Carlo simulations of analyses for $T S 5_{1950}+\mathrm{AR}(1)$ noise based on actual tide gage noise characteristics.

A dimensionless form of the $\operatorname{SLRD}\left(t_{c}, \boldsymbol{\tau}\right)$ time series is given by

$$
\frac{\left\langle S L R D\left(t^{\prime}, \tau\right)\right\rangle}{\max \left(\left|\left\langle S L R D\left(t^{\prime}, \tau\right)\right\rangle\right|\right)}
$$

with

$$
t^{\prime}=\frac{t_{c}-t_{s}}{\tau}
$$

where $t_{s}$ is the time of the rate change, the straight line bracket indicates absolute value, and the angled brackets represent ensemble averaging over the simulations. Results illustrate that the estimated magnitude of the rate change is a function of the separation between $t_{c}$, the central year of the regression window, and the year of the rate change, $t_{s}$, normalized by the window duration (fig. 14). The rate change is captured in its entirety at $t_{c}=t_{s}$. Rate changes occurring relatively distant in time from $t_{c}$ will have a much reduced magnitude and will therefore be more difficult to differentiate from 0 . For $A_{R B M}$ and $A_{S Q R M}$ analyses, where the rate change occurs defines the width of the bias error bands shown in figure 6 . This also illustrates why the $A_{Q R M}$ analysis (or $S L R D$ and $A_{S Q R M}$ analyses with relatively large $\tau$ ) of a long time series, which includes a longer time period prior to the acceleration and thus forces $t_{c}$ (the central time of the record in the case of $\mathrm{A}_{\mathrm{QRM}}$ ) far from $t_{s}$, may not show a significant acceleration if the acceleration is initiated in the recent past while a shorter time series (which forces $t_{c}$ closer to $t_{s}$ ) will allow detection of such an event (Houston and Dean (2011a, b); Rahmstorf and Vermeer (2011); Sallenger and others (2012)). $A_{Q R M}$ estimates based on a sample with different start and (or) end dates (thus different $\tau$ and (or) $t_{c}$ ) and time-varying acceleration are not expected to be equivalent, even in the absence of noise. The practical implications are straightforward: (1) comparision of acceleration estimates between 

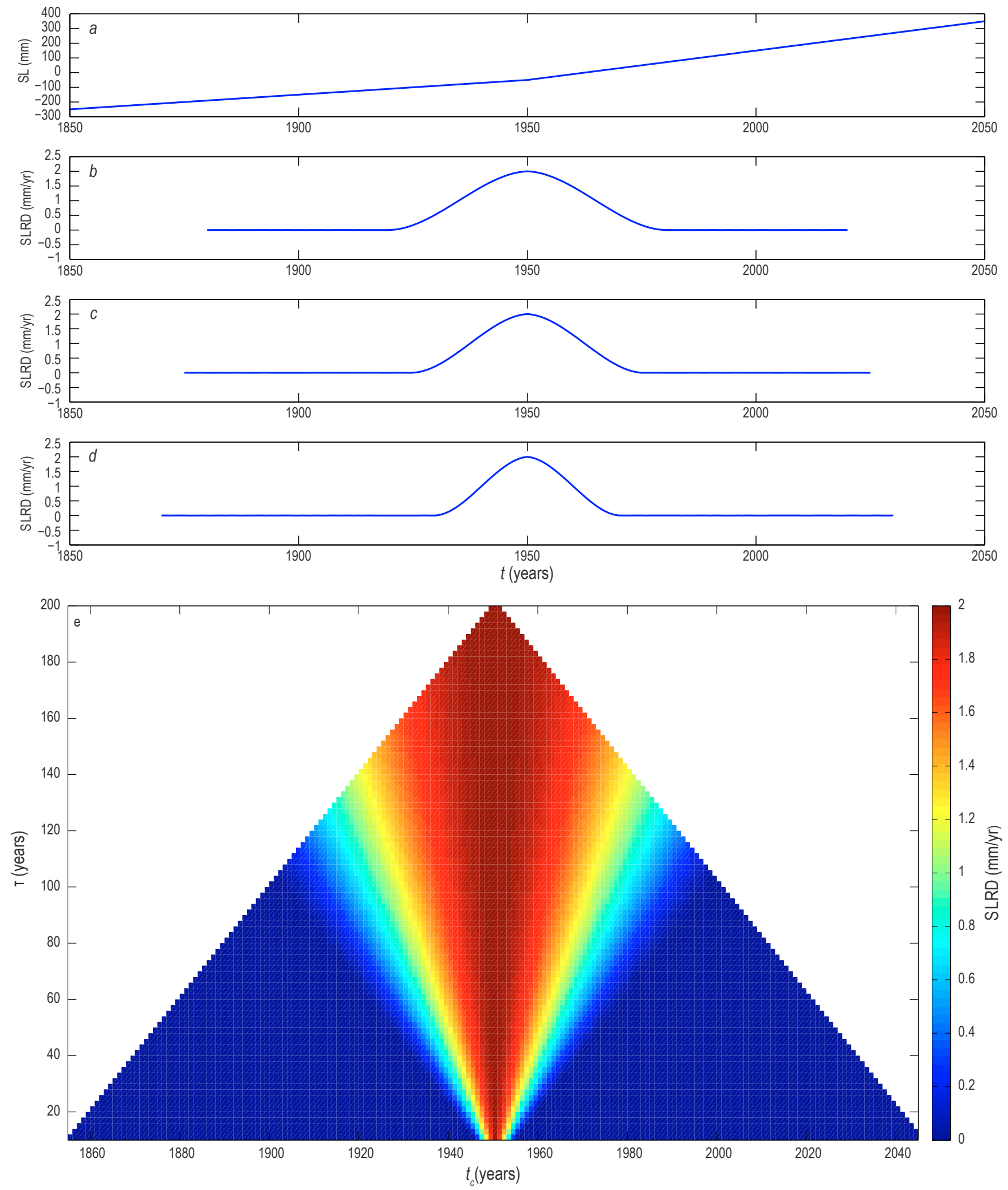

Figure 12. $\operatorname{SLRD}\left(t_{c}, \tau\right)$ results for $\mathrm{TS}_{1950}$ (no noise). (a) $\operatorname{TS5}_{1950^{\circ}}$ (b) $\operatorname{SLRD}\left(t_{c^{\prime}}, 60\right)$. (c) $\operatorname{SLRD}\left(t_{c^{\prime}}, 50\right)$. (d) $\operatorname{SLRD}\left(t_{c}, 40\right)$. (e) $\operatorname{SLRD}\left(t_{c}, \tau\right)$. [mm, millimeter; mm/yr, millimeters per year] 
tide gages should be made only for records (or windows) with identical start and end dates, and (2) it should be recognized that any change in acceleration occurring near the (relative) beginning or end of the record/window will be significantly underestimated and thus difficult to detect. Given that sea-level rise acceleration would be expected to occur more recently in the tide gage records, this latter point argues for the use of shorter records (or analysis windows) for the detection of recent acceleration in $S L$ time series in order to allow for the range of $t_{c}$ to include values close or equal to times of possible step changes in $S L R\left(t_{s}\right)$.

For the regression methods presented here, the influence of noise can be approached from two conceptual directions as it relates to signal detection. First is the error surrounding any estimate of $A$ or $S L R D$. The variance of the residual errors from the regression solution (eqs. 3, 7, 8) propagates to the error in the sample estimate of the acceleration (eq. 9), or rate difference (eq. 11). Figure 14 shows that for a step increase in rate (TS5), the most accurate estimate of SLRD occurs for the regression window centered on $t_{s}$. The first approach suggests a ratio to compare the magnitude of the sampling error for $\operatorname{SLRD}\left(t_{c}=t_{s}, \boldsymbol{\tau}\right)$ to the magnitude of the $S L R D$. For the Monte Carlo simulations this comparison would be shown as

$$
\frac{2 \sigma_{M C\left\langle S L R D\left(t_{c}=t_{s}, \tau\right)\right\rangle}}{\left|\left\langle S L R D\left(t_{c}=t_{s}, \tau\right)\right\rangle\right|}
$$
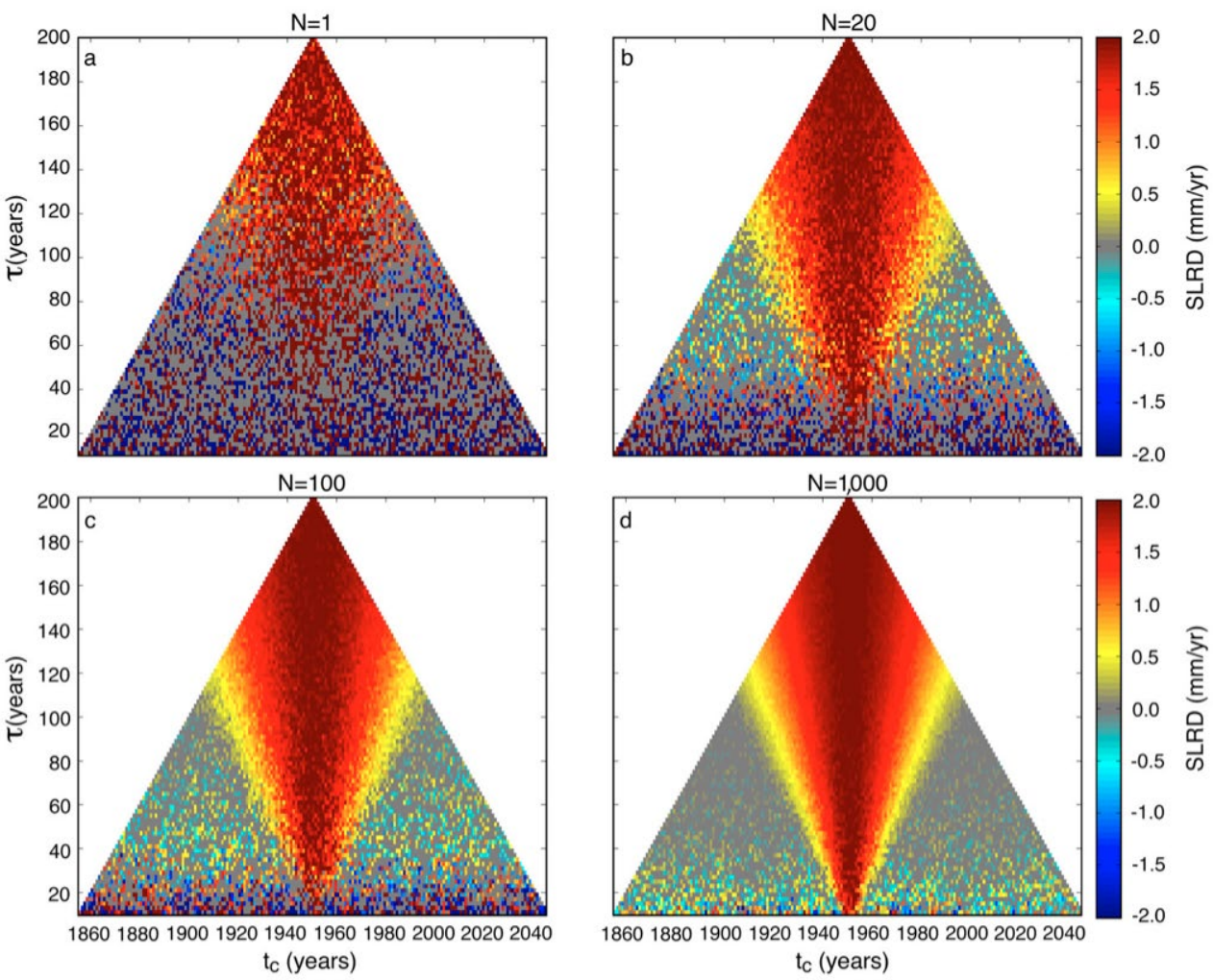

Figure 13. SLRD estimates for time series TS5 ${ }_{1950}$ with Guassian (white) noise at $100 \%$ observed level. Compare to figure $12 \mathrm{e}$ (but note color scale is different.) $1 \sigma$ error mask applied (values set to 0 if not statistically different than 0). (a) $\mathrm{N}=1$. (b) $\mathrm{N}=20$. (c) $\mathrm{N}=100$. (d) $\mathrm{N}=1,000$. [mm/yr, millimeters per year] 

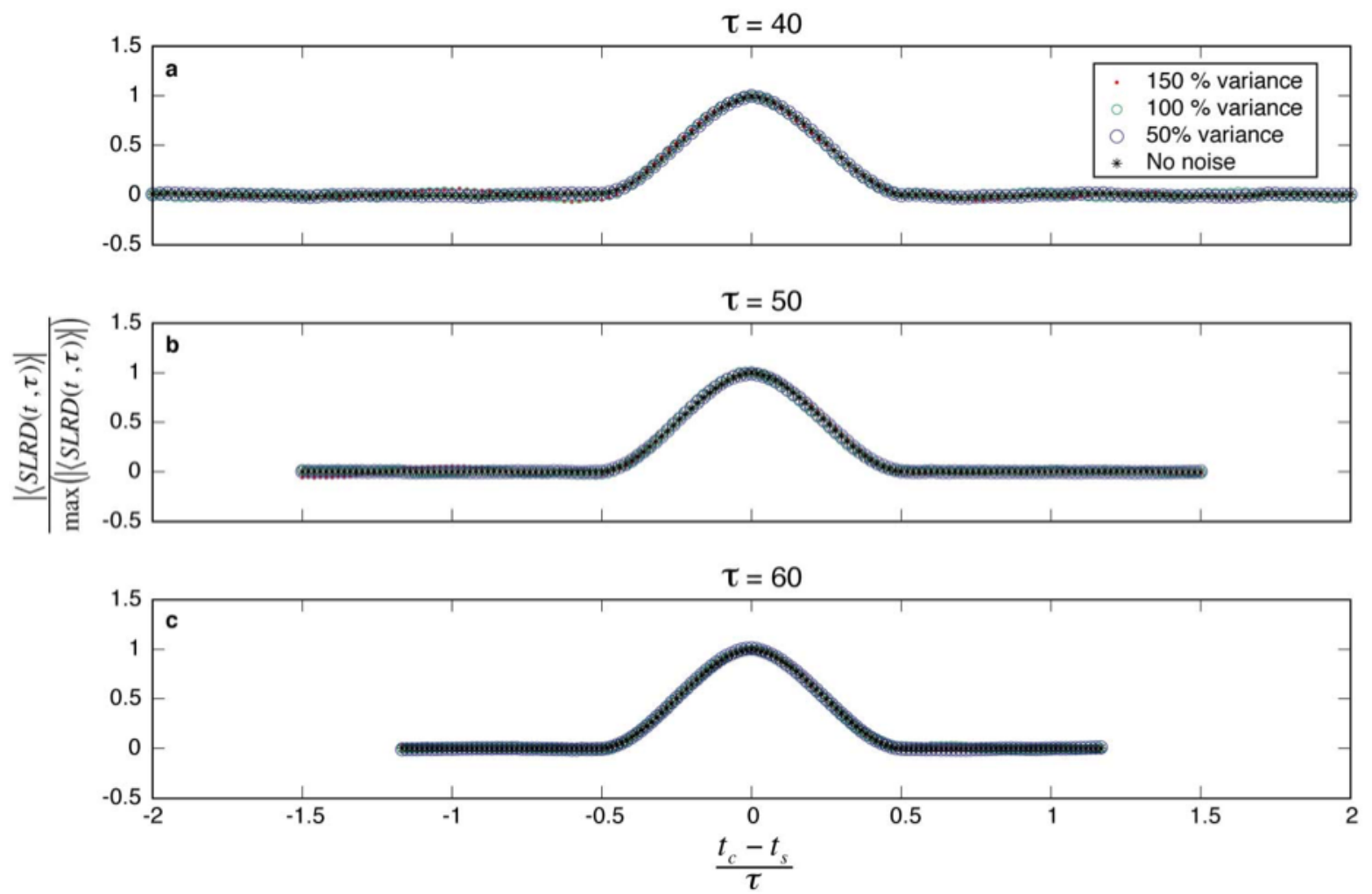

Figure 14. Dimensionless representation of ensemble-averaged SLRD time series with multiple AR(1) noise levels $\left(0,50,100,150\right.$ percent of observed) and different window lengths for TS5 $_{1950^{\circ}}$ (a) $\tau=40$ years. (b) $\tau=50$ years. (c) $\tau=60$ years. The probability of detecting the rate difference is maximized at $t_{c}=t_{s}$.

This provides a representation of the significance of a single estimate of $\operatorname{SLRD}\left(t_{c}=t_{s}, \boldsymbol{\tau}\right)$ in the presence of noise (see figure 10 for associated examples of PDFs). At a value of 1.0, the estimated SLRD would equal the $2 \sigma$ error; values less than 1 increasingly provide confidence that the $S L R D$ estimate is different than 0 . Shorter regression windows and low SLRD magnitudes, as expected, more commonly result in $S L R D$ estimates not significantly different than 0.

A second conceptual approach to noise-to-signal ratio compares the variance of the residuals about the regression to the variance added by the rate increase. The focus here is on the relative separation between the point cloud surrounding the signal with the changed rate and the (assumed) point cloud had there been no rate increase (fig. 15), which can be expressed as

$$
\frac{2 \sigma_{M C A R(1)}}{\mid\left\langle S L R D\left(t_{c}=t_{s}, \tau\right)\right\rangle * \tau}
$$


Equation 15 represents the magnitude of the noise (residual) variance, $\sigma_{M C A R(1)}$, relative to the increase in the magnitude of the signal resulting from the change in rate. Assuming time-invariant Gaussian noise at a value of 1.0, the $2 \sigma$ noise envelope around the increased sea-level trend will separate from the extension of the original trend (fig. 15; this value is conceptually useful but not a statistical requirement for rate change detection). The $2 \sigma$ envelopes around the extension of the first and second regression segments separate at a ratio of 0.5 . This representation of noise-to-signal ratio suggests detection of smaller magnitude rate changes (relative to a fixed noise level) will require longer regression windows to allow for larger increases in signal variance. Contrary to the guidance discussed here, these considerations argue for longer records.

To summarize, estimates of SLRD or $A$ using the regression methods developed here are sensitive to the relative separation between the center of the regression window and the year of any change in acceleration. Short regression windows confine the influence of the rate change to a narrower range of years, decreasing potential bias errors for $t_{c} \neq t_{s}$. However, estimates from shorter records are more widely distributed around the expected mean value. Longer windows, while extending potential bias error to a wider range of years, provide more accuracy in the determination of the magnitude of change through improved signal-to-noise ratios.

Three primary options exist to reduce random error (and increase confidence) in the $R B M$ estimates. The first option is to average results from a collection of independently operated gages that can be reasonably assumed to be subject to the same forcing, be it on a regional or global scale (for example, Sallenger and others (2012) and Church and White (2011), respectively). Assuming $M$ gages are independent samples from the same statistical population of interest (for example, that the signals in the time series are well correlated, whereas the residuals are not), the error of their mean will roughly decrease by a factor of ( $M^{-\frac{1}{2}}$ ) relative to the errors of the individual gages (demonstrated in figures 12 and 13). Second, the regression window length can be increased, resulting in smaller random errors but

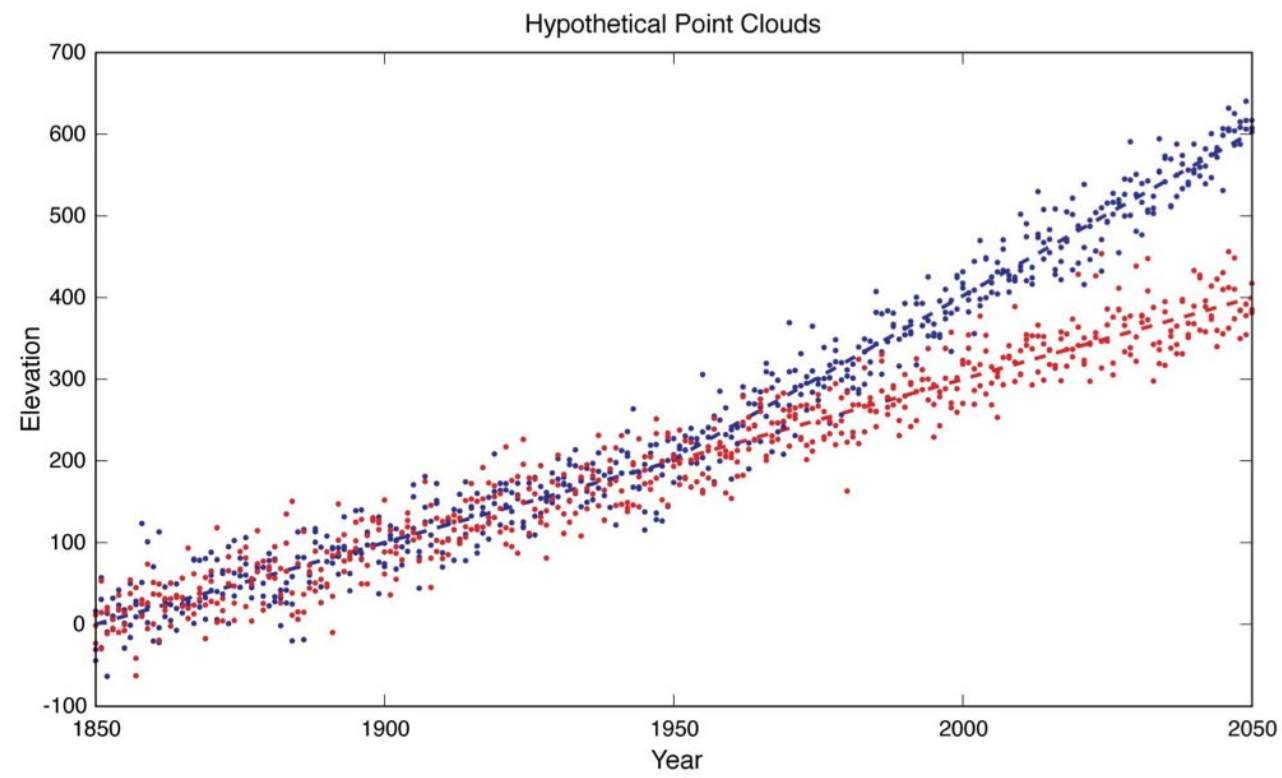

Figure 15. Hypothetical time series showing the gradual separation of point clouds after a rate increase from $2 \mathrm{~mm} / \mathrm{yr}$ (red) to $4 / \mathrm{mm}$ yr (blue) at year 1950. The ability to detect the rate change is proportional to the magnitude of the rate difference and the length of the sample window and inversely proportional to the magnitude of the noise. [mm/yr, millimeters per year] 
at the expense of degraded temporal resolution and potentially increased bias. Third, the data can be carefully filtered to remove the unwanted coherent signals and statistical noise not of interest to the investigation (Hamlington and others, 2010). Authors are encouraged to clearly state the limitations of their methodology relative to the hypotheses to be tested or evaluated. The appropriate mix of methods will depend to a large extent on the specific objectives of the user. Scientists interested in global sealevel rise over the historical record may well choose different methodology than coastal land-use planners focused on short-term, community-based issues.

\section{SQRM and RBM Acceleration Estimates for Periodic Signals}

Although this report focuses on techniques for capturing recent abrupt transitions in the climate system (and thus in $S L$ ) and the detectability of the potentially accelerating $S L$, it is also important to understand how the methodologies handle periodic signals.

$S L R D, A_{R B M}$, and $A_{S Q R M}$ estimates use two time scales. The first, $\boldsymbol{\tau}$, is the length of the sliding regression window and, for conceptual purposes, can be thought of as being analogous to the duration of a weighted moving-average filter. The second time scale, $\boldsymbol{\Delta} \boldsymbol{\tau}$, is the time step used to slide the regression window through the $S L$ time series and controls the sample density (or temporal resolution) of the resulting rate difference estimates. A simple example for $S L R D$ is illustrative (fig. 16). For the case of a sinusoid with amplitude $A$ and period $T=30$ years, a window of $\tau=T=30$ stepped through the time series at $\boldsymbol{\Delta} \boldsymbol{\tau}=1$ year will oscillate between $\pm 8 A / T$. The sampling of the oscillatory signal is controlled by the magnitude of $\boldsymbol{\Delta} \boldsymbol{\tau}$, as there will be $T / \boldsymbol{\Delta} \boldsymbol{\tau}$ estimates per cycle, and $\boldsymbol{\Delta} \boldsymbol{\tau}$ must be small enough to define the oscillation. Note the temporal resolution is independent of $\boldsymbol{\tau}$, the regression window length. With a regression window of duration $\boldsymbol{\tau}=2 T$, the rate differences will be nearly zero as each half-window rate covers a complete cycle of the oscillation. In the case of a pure sinusoid, the next local rate difference amplitude maxima occurs for a regression window of duration $\boldsymbol{\tau}=3 T$. However, due to the increased window length and the associated decrease in slope of the regression lines, the rate difference magnitudes for this oscillation will have dropped by a factor of 3 relative to $\tau=30$. In addition, if the rate differences are converted to accelerations by multiplying by $(2 / \tau)$, the amplitude decay of the signal is even more rapid as $\boldsymbol{\tau}$ increases away from the fundamental period of the oscillation.

The results for a variety of periodic signal shapes are shown for $\operatorname{SLRD}\left(t_{c}, \boldsymbol{\tau}\right)$ in figure $17 \mathrm{a}-\mathrm{g}$ and for $A_{S Q R M}\left(t_{c}, \tau\right)$ in figure $19 \mathrm{a}-\mathrm{d}$. In these cases the fundamental period, $T$, is 25 years and $\Delta \boldsymbol{\tau}=1$ year. Duration $\tau$ is varied from 10 to 200 years in even-numbered increments and the results are plotted with the central year of the sliding regression window on the horizontal axis and the value of $\boldsymbol{\tau}$ on the vertical axis. There are two common results for all these single-frequency test cases: (1) the periodicity of the acceleration and rate difference oscillations remains 25 years, though some do exhibit interesting structure within that period, and (2) the 25-year oscillations are effectively damped before $\tau$ approaches $2 T$.

Although the SLRD method also has some ability to separate the contributions of two sinusoids (figs. $17 \mathrm{~h}-\mathrm{i}, 19 \mathrm{~h}-\mathrm{i}$ ), as could be expected, results improve as the difference between the periods increases. The distinction between oscillations with periods of 10 and 70 years is very clear (figs. $17 \mathrm{~h}$, 19h). The results show a surprising ability to distinguish between signals of equal amplitudes with periods of 30 and 50 years. The 30-year period dominates for $\tau<35$, and the 50 -year period dominates for $\boldsymbol{\tau}>45$ years, with a transition region from roughly $35<\boldsymbol{\tau}<45$ years (figs. 17i, 18, 19i).

Previous research has indentified two relatively energetic oscillations in sea-level elevation centered at periods of 20-30 years and 50-70 years (summarized in Frankcombe and Dijkstra, 2009). Time series are constructed with these periodicities (amplitude of $10 \mathrm{~mm}$, periods of 25 and 60 years) 

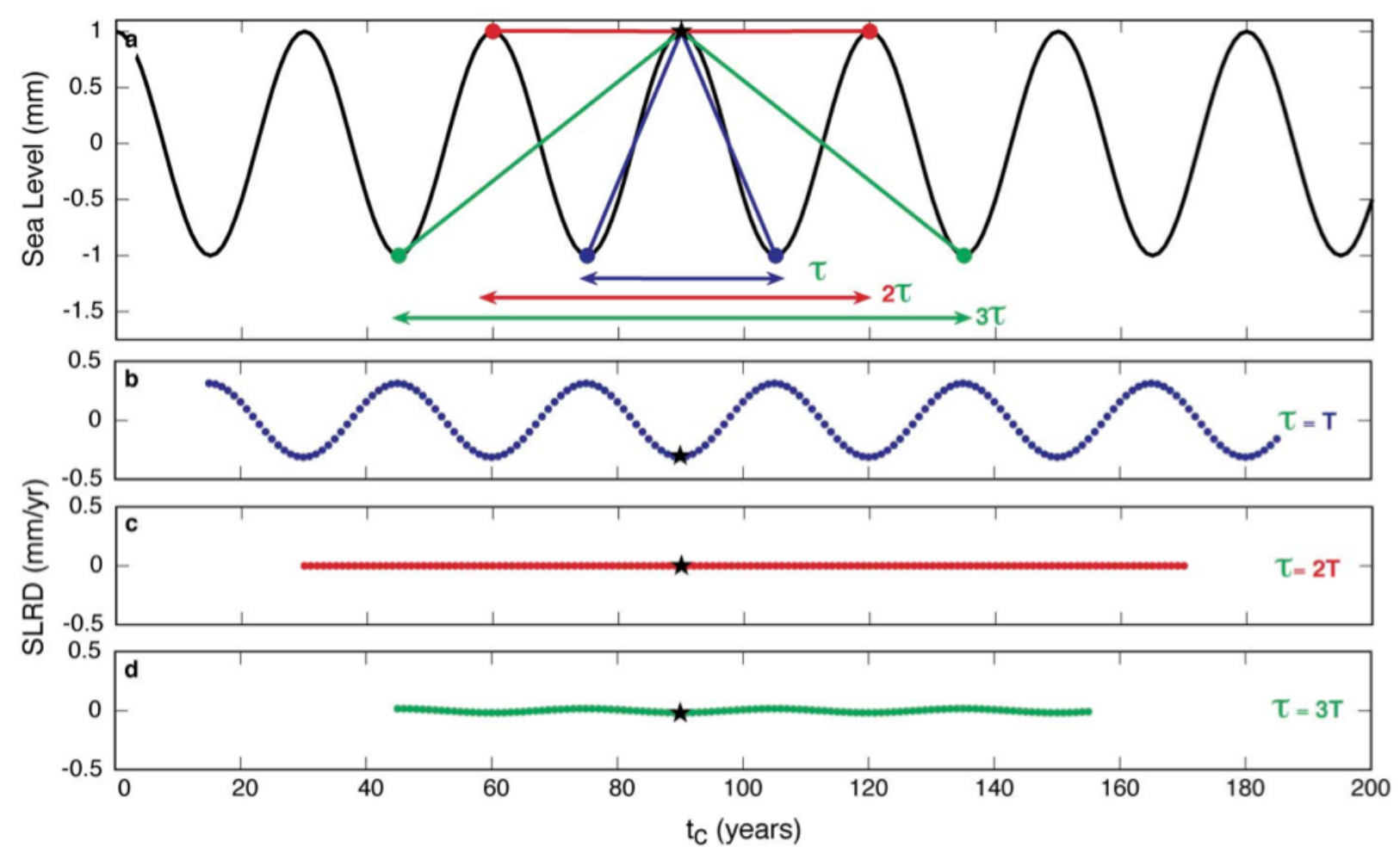

Figure 16. A simple example of $S L R D$ representation of a periodic fluctuation in sea level. $\Delta \tau=1$ year in all cases. a: Sea-level time series with representations of the regression line segments for $\tau=T$ (blue), $\tau=2 T$ (red), and $\boldsymbol{\tau}=3 T$ (green) for a common central year, $t_{c}=90$ years. b: SLRD time series for $\tau=T$ (30 years). c: SLRD time series for $\tau=2 T$ (60 years). d: SLRD time series for $\boldsymbol{\tau}=3 T$ (90 years). [mm, millimeters; mm/yr, millimeters per year]

both alone and combined with two rate increase time series TS5 ${ }_{1950}$ and $\mathrm{TS}_{2000}$. Both periodicities and the rate change can be identified in the $S L R D$ analyses (fig. 20). The rate increases are most obvious for $\tau>50$ years. The addition of TS5 ${ }_{1950}$ (fig. 20b) results in larger values for $S L R D$ near the time of the rate increase, visibly altering the oscillatory signal in the region enclosed by $1930<t_{c}<1970$ and $50<\boldsymbol{\tau}<$ 200. Moving the rate increase toward the end on the time series $\left(\mathrm{TS}_{2000}\right.$, fig. 20c) results in a similar increase to the oscillatory results. The negative acceleration centered near $t=1995, \boldsymbol{\tau}=60$ in figure 20a is now completely masked by the rate increase in figure 20c. Increased $S L R D$ values are also seen for the larger region roughly defined by $\boldsymbol{\tau}>50$ and $t_{c}>1980$. 

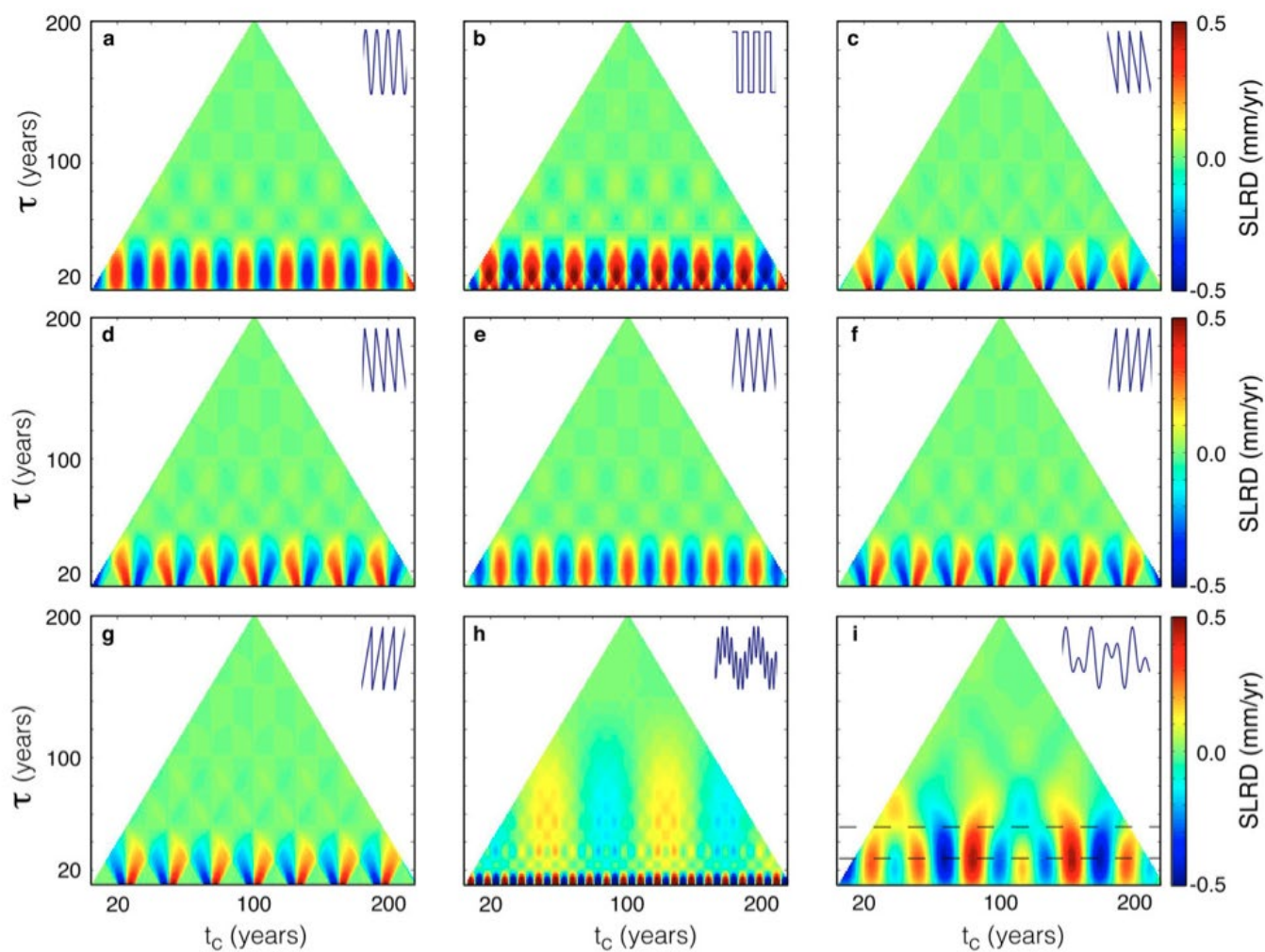

Figure 17. $S L R D\left(t_{c}, \tau\right)$ for representative periodic signals. Example segments of each $S L$ time series are shown in the upper right of each panel. a: $\sin , T=25$ years; b: square wave, $T=25$ years; c-g: sawtooth waves with different symmetry properties, all have $T=25$ years; h: sum of $2 \sin$ waves, $T=10$ and $T=70$ years; i: sum of $2 \sin$ waves, $T=30$ and $T=50$ years. Dashed lines indicate locations of $S L R D$ time series shown in figure 18. [mm/yr, millimeters per year]
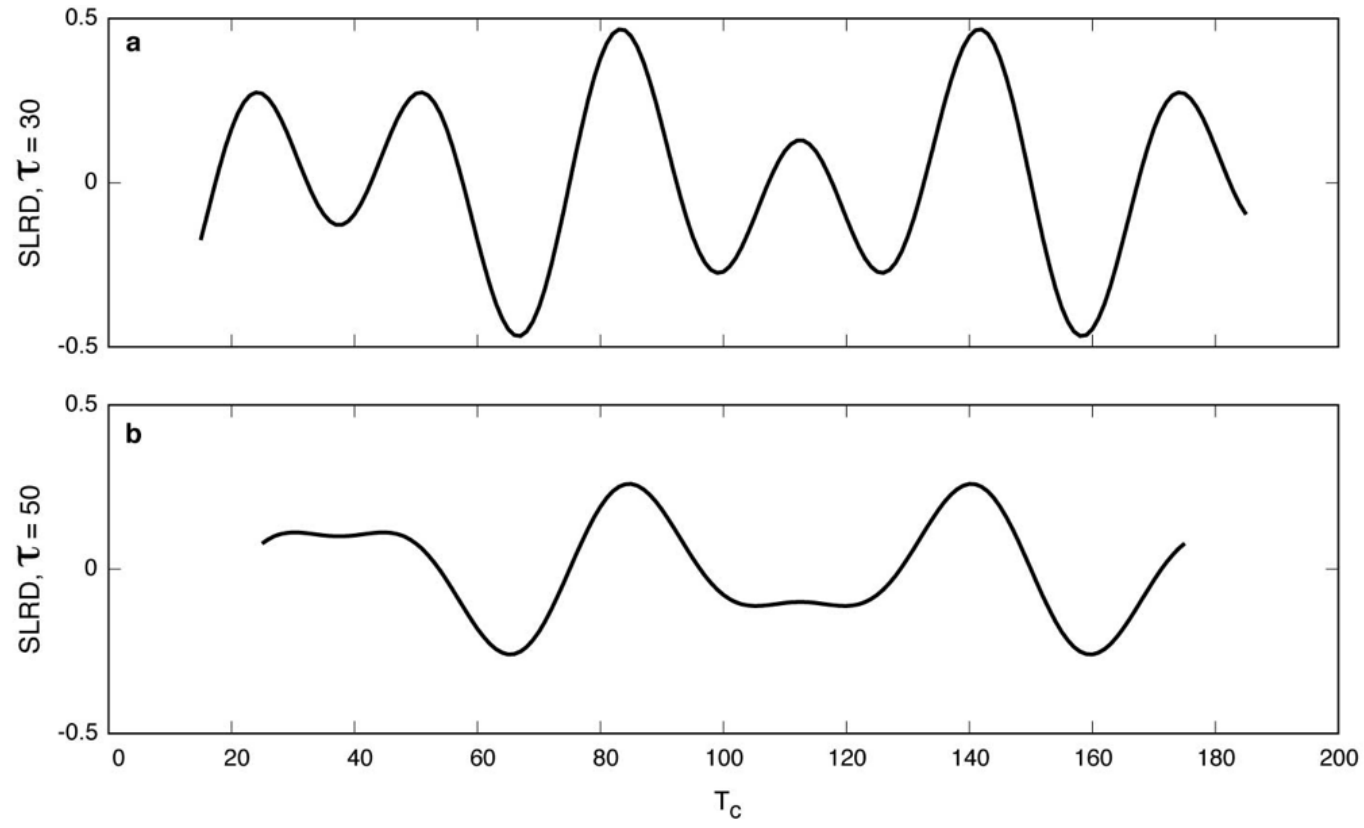

Figure 18. SLRD time series slices at $\boldsymbol{\tau}$ for the two known periods from figure 17i. (a) $\tau=30$; (b) $\boldsymbol{\tau}=50$. Note that the 30-year periodicity is significantly damped for $\tau=50$. 

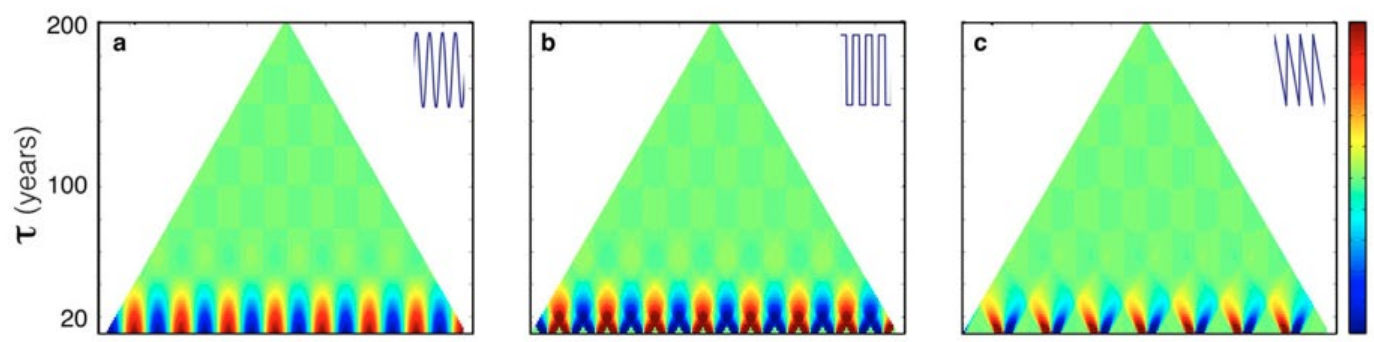

0.05
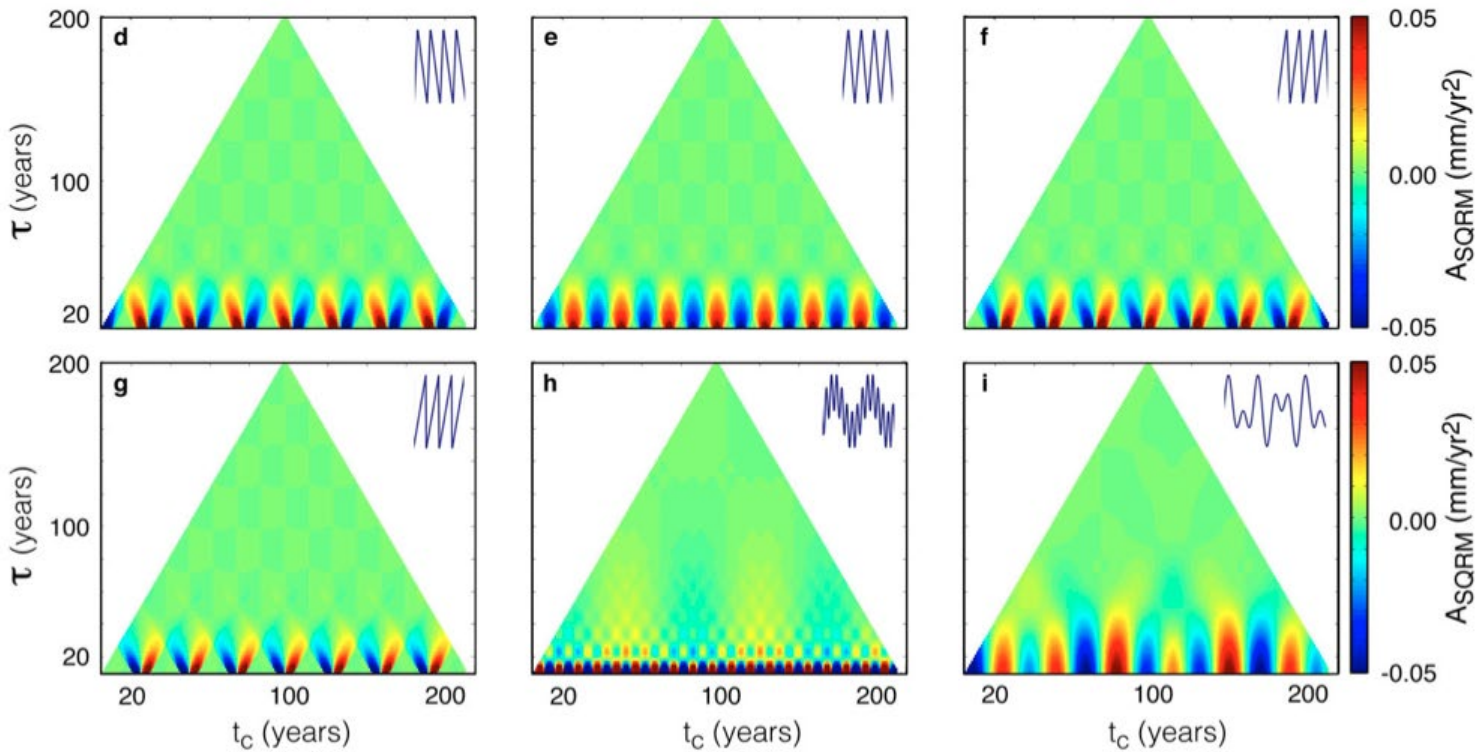

Figure 19. $A_{\text {SRRM }}\left(t_{c}, \tau\right)$ for representative periodic signals. Example segments of each $S L$ time series are shown in the upper right of each panel. a: sin, $T=25$ years; b: square wave, $T=25$ years; c-g: sawtooth waves with different symmetry properties, all have $T=25$ years; h: sum of $2 \sin$ waves, $T=10$ and $T=70$ years; i: sum of $2 \sin$ waves, $T=30$ and $T=50$ years. [mm/yr², millimeters per year squared]

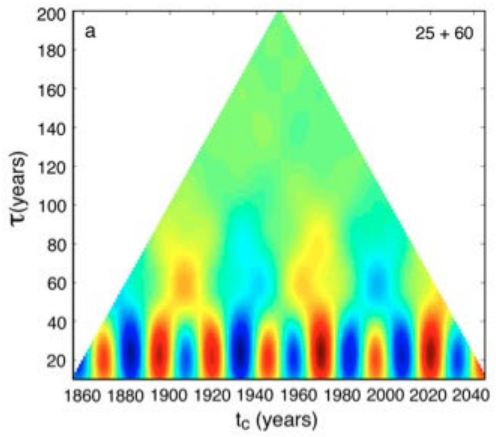

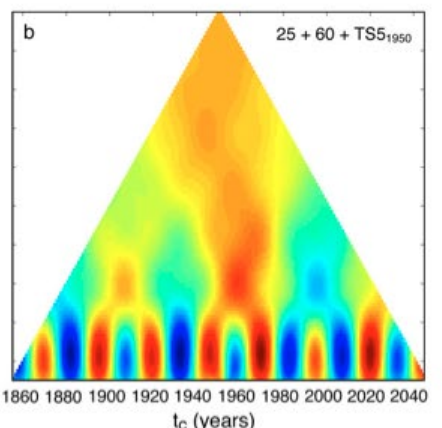

$t_{c}$ (years)

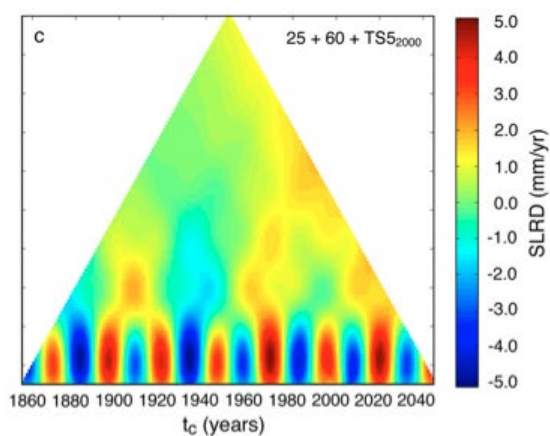

$t_{c}$ (years)

Figure 20. $\operatorname{SLRD}\left(t_{c^{\prime}} \tau\right)$ calculations for oscillatory time series with different rate increase scenarios. (a) No rate increase. (b) Rate increase at year 1950. (c) Rate increase at year 2000. [mm/yr, millimeters per year] 


\section{Summary}

The single-fit implementation of $Q R M$ can result in biased estimates of $A_{S L}(t)$ if changes in acceleration exist within the time series. This bias is a critical shortcoming of the technique if $A_{Q R M}$ estimates are compared between records of different lengths or with different start and (or) end dates. The $R B M$ and $S Q R M$ methods are not biased with respect to the timing of acceleration except if the acceleration occurs in the blanking region at the beginning or end of the record where no estimates are made or as $\boldsymbol{\tau}$ approaches the total length of the record. $R B M / S Q R M$ biases in the synthetic time series tests are associated with the smoothing of abrupt changes in acceleration.

The magnitude and timing of simple changes in acceleration can be recovered from the $A_{R B M}\left(t_{c}, \boldsymbol{\tau}\right)$ series given an appropriate choice(s) for $\boldsymbol{\tau}$. Varying $\boldsymbol{\tau}$ can guide the choice of an appropriate window, depending on the periodicity of the signal or noise. Conversely, as seen in the periodic time series tests, contributions from multiple changes in acceleration can be poorly resolved depending on their separation in time relative to the choice of $\boldsymbol{\tau}$. The primary deterrent to using the shorter regression windows is the small signal-to-noise ratio in tide gage records. Regional averaging can be used to increase confidence in $A_{R B M}$ estimates.

\section{References Cited}

Bendat, J.S., and Piersol, A.G., 1986, Random data-Analysis and measurement procedures: New York, John Wiley \& Sons, 566 p.

Church, J.A., and White, N.J., 2006, A 20th century acceleration in global sea level rise: Geophysical Research Letters, v. 33, L01602, doi:10.1029/2005GL024826.

Church, J.A., and White, N.J., 2011, Sea-level rise from the late 19th to the early 21 st century: Surveys in Geophysics, doi:10.1007/s10712-011-9119-1.

Dasgupta, S., laplante, B., Meisner, C., Wheeler, D., and Yan, J., 2007, The impact of sea level rise on developing countries - A comparative analysis: World Bank Policy Research Working Paper 4136.

Douglas, B.C., 1991, Global sea level rise: Journal of Geophysical Research, v. 96, p. 6981-6992.

Douglas, B.C., 2001, Sea level change in the era of the recording tide gauge, in Douglas, B.C., Kenney, M.S., and Leatherman, S.P., eds., Sea level rise: International Geophysics, v. 75, p. 37-64, doi:10.1016/S0074-6142(01)80006-1.

Edwards, R., 2008, Sea levels_-Science and society: Progress in Physical Geography, v. 32, p. 557-574.

Foster, G., and Rahmstorf, S., 2011, Global temperature evolution 1979-2010: Environmental Research Letters, v. 6, 044022, doi:10.1088/1748-9326/6/4/044022.

Frankcombe, L., and Dijkstra, H., 2009, Coherent multidecadal variability in North Atlantic sea level: Geophysical Research Letters, v. 36, L15604, doi:10.1029/2009GL039455.

Frazier, T.G., Wood, N., Yarnal, B., and Bauer, D.H., 2010, Influence of potential sea level rise on societal vulnerability to hurricane storm-surge hazards, Sarasota County, Florida: Applied Geography, v. 30, p. 490-505, doi:10.1016/j.apgeog.2010.05.005.

Hamlington, B.D., Leben, R.R., and Nerem, R.S., 2010, The effect of signal-to-noise ratio on the study of sea level trends: Journal of Climate, v 24, p. 1396-1408, doi:10.1175/2010JCLI3531.1.

Holgate, S.J., and Woodworth, P.L., 2004, Evidence for enhanced coastal sea level rise during the 1990s: Geophysical Research Letters, v. 31, L07305, doi:10.1029/2004GL019626. 
Houston, J.R., and Dean, R.G., 2011a, Sea-level acceleration based on U.S. tide gauges and extensions of previous global-gauge analyses: Journal of Coastal Research, v. 27, p. 409-417, doi:10.2112/ JCOASTRES-D-10-00157.1.

Houston, J.R., and Dean, R.G., 2011b, Reply to: Rahmstorf, S., and Vermeer, M., 2011, Discussion of: Houston, J.R., and Dean, R.G., 2011, Sea-level acceleration based on U.S. tide gauges and extensions of previous global-gauge analyses: Journal of Coastal Research, v. 27, no. 3, p. 409-417, doi:10.2112/ JCOASTRES-D-11A-00008.1.

Jevrejeva, S., Grinsted, A., Moore, J.C., and Holgate, S., 2006, Nonlinear trends and multiyear cycles in sea level records: Journal of Geophysical Research, v. 111, C09012, doi:10.1029/2005JC003229.

Jevrejeva, S., Moore, J.C., Grinsted, A., and Woodworth, P.L., 2008, Recent global sea level acceleration started over 200 years ago? Geophysical Research Letters, v. 35, L08715, doi:10.1029/2008GL033611.

Maul, G.A., and Martin, D.M., 1993, Sea level rise at Key West, Florida, 1846-1992-America's longest instrument record? Geophysical Research Letters, v. 20, p. 1955-1958.

Merrifield, M.A., Merrifield, S.T., and Mitchum, G.T., 2009, An anomalous recent aceeleration of global sea level: Journal of Climate, v. 22, p. 5772-5781, doi:10.1175/2009JCLI2985.1.

Rahmstorf, S., and Vermeer, M., 2011, Discussion of: Houston, J.R., and Dean, R.G., 2011, Sea-level acceleration based on U.S. tide gauges and extensions of previous global-gauge analyses: Journal of Coastal Research, v. 27, no. 3, p. 409-417, doi:10.2112/JCOASTRES-D-11-00082.

Sallenger, A.H., Doran, K.S., and Howd, P.A.. 2012, Hotspot of accelerated sea-level rise on the Atlantic coast of North America: Nature Climate Change, v. 2, p. 884-888, doi: 10.1038/nclimate1597.

Watson, P.J., 2011, Is there evidence yet of acceleration in mean sea level rise around mainland Australia? Journal of Coastal Research, v. 27, p. 368-377, doi:10.2112/JCOASTRES-D-10-00141.1.

Woodworth, P.L., 1990, A search for accelerations in records of European mean sea level: International Journal of Climatolology, v. 10, p. 129-143.

Woodworth, P.L., Menendez, M., and Gehrels, W.R., 2011, Evidence for century-timescale acceleration in mean sea levels and for recent changes in extreme sea levels: Surveys in Geophysics, v. 32, no. 4, p. 603-618, doi:10.1007/s10712-011-9112-8.

Woodworth, P.L., White, N.J., Jevrejeva, S., Holgate, S.J., Church, J.A., and Gehrels, W.R., 2009, Evidence for the accelerations of sea level on multi-decade and century timescales: International Journal of Climatology, v. 29, p. 777-789, doi:10.1002/joc.1771.

Zervas, C., 2009, Sea level variations of the United States 1854-2006: National Oceanic and Atmospheric Adminsitration Technical Report NOS CO-OPS 053, [variously paged]. 


\section{Glossary}

$A_{\text {QRM }}$ Average acceleration calculated using a single quadratic regression.

$A_{R B M}$ Acceleration calculated using the rate-based method.

$A_{S L} \quad$ The true acceleration of a sea-level record.

$\boldsymbol{A}_{\text {SQRM }}$ Acceleration calculated using the sliding quadratic regression window.

GSL Global sea level. This measure is assumed to be free from the effects of vertical land motion.

QRM Quadratic regression method. Refers to the use of a single second order regression equation to estimate the average acceleration over the entire record length.

RBM Rate-based method. A method for calculating acceleration based on a sliding regression window and the differencing of two rates (first half, second half) calculated using linear regression. Similar to the sliding quadratic regression method.

SL Relative sea level. This elevation measure is recorded by tide gages and includes any land motion.

SLR Sea-level rise.

SLRD Sea-level rate difference. The arithmatic difference between two successive estimates of the rate of sea-level rise. SLRD is referenced to the central time of those two rates and to the length of the combined interval that formed the basis for the rate estimates.

SQRM (SQM) Sliding quadratic regression method. A quadratic regression method where multiple second order regressions are calculated by sliding a regression window through the time series. The calculated accelerations are estimates of the local average and associated with the time at the center of the window. 
